\title{
Implementing Ultrasound Imaging for the Assessment of Muscle and Tendon Properties in Elite Sports: Practical Aspects, Methodological Considerations and Future Directions
}

\author{
Fabio Sarto $^{1}$ Jörg Spörri' ${ }^{2,3}$ • Daniel P. Fitze ${ }^{2}$ Jonathan I. Quinlan ${ }^{4,5} \cdot$ Marco V. Narici $^{1,6} \cdot$ Martino V. Franchi $^{1}$ (1)
}

Accepted: 6 February 2021 / Published online: 8 March 2021

(c) The Author(s) 2021

\begin{abstract}
Ultrasound (US) imaging has been widely used in both research and clinical settings to evaluate the morphological and mechanical properties of muscle and tendon. In elite sports scenarios, a regular assessment of such properties has great potential, namely for testing the response to training, detecting athletes at higher risks of injury, screening athletes for structural abnormalities related to current or future musculoskeletal complaints, and monitoring their return to sport after a musculoskeletal injury. However, several practical and methodological aspects of US techniques should be considered when applying this technology in the elite sports context. Therefore, this narrative review aims to (1) present the principal US measures and field of applications in the context of elite sports; (2) to discuss, from a methodological perspective, the strengths and shortcomings of US imaging for the assessment of muscle and tendon properties; and (3) to provide future directions for research and application.
\end{abstract}

Fabio Sarto and Jörg Spörri shared co-first authorship.

Martino V. Franchi

martino.franchi@unipd.it

1 Department of Biomedical Sciences, University of Padova, Padova, Italy

2 Sports Medical Research Group, Department of Orthopaedics, Balgrist University Hospital, University of Zurich, Zurich, Switzerland

3 Department of Orthopaedics, University Centre for Prevention and Sports Medicine, Balgrist University Hospital, University of Zurich, Zurich, Switzerland

4 School of Sport, Exercise and Rehabilitation Sciences, University of Birmingham, Birmingham, UK

5 National Institute for Health Research, Birmingham Biomedical Research Centre at University Hospitals Birmingham NHS Foundation Trust, Birmingham, UK

6 CIR-MYO Myology Centre, University of Padova, Padova, Italy

\section{Key Points}

Assessment of muscle and tendon properties using ultrasound imaging may present many different advantageous applications in an elite sports scenario.

In an elite sports context the application of ultrasound is challenging, and thus several practical and methodological recommendations should be considered for its implementation.

\section{Introduction}

Ultrasound (US) imaging represents a relatively affordable, non-invasive, in-vivo method for examining the morphological and mechanical properties of muscle and tendon [1, 2]. Pioneering studies employing US to study musculoskeletal structure and function were conducted in the 1960s [3]; however, its systematic use became more prominent in the 1990s [4-6]. In particular, brightness mode (B-mode) US technique has become widely adopted to quantify skeletal muscle mass and architecture [4, 6, 7] (and their relation 
with muscle function $[8,9])$ in different populations. More recently, researchers have attempted to quantify muscle and tendon behaviours during dynamic tasks such as walking, running, jumping, cycling and swimming [2, 10, 11]. In addition, advancements in US technology such as the extended-field-of-view technique (EFOV), 3D US, shearwave elastography (SWE) imaging and developments in data processing have enabled deeper insight into the structural and functional properties of muscles and tendons. All of these new technical developments are associated with various benefits, but also with relevant drawbacks and limitations (for an in-depth review of such aspects we refer the reader to Franchi et al. [1]).

In elite sport settings, the assessment of muscle and tendon anatomical and mechanical properties has a great potential for: (1) testing athletes' status with respect to performance-related factors and their response to training; (2) detecting athletes at higher risks of injury; (3) screening athletes for structural abnormalities related to current (or future) musculoskeletal complaints; and (4) monitoring their return to sport after a musculoskeletal injury. However, in elite sports, the time for such assessments is generally scant, resources and equipment may be limited, and the operators are often not trained for such specific US evaluations. Therefore, the application of US for muscle and tendon assessment in these contexts remains challenging.

Accordingly, this narrative review aims to (1) summarize common principal US measures and field of applications in the context of elite sports; (2) highlight from a methodological perspective the strengths and limitations of US imaging for the assessment of muscle and tendon properties; and (3) provide future directions of research and application. Target audience is sport scientists, researchers, as well as elite sports and sports medicine practitioners.

\section{Practical Aspects}

\subsection{Principal Ultrasound-Based Measures}

In this section, we present most of the principal indices/ measures of muscle-tendon morphological and mechanical properties that can be acquired when using US. Their physiological role is then briefly described from a functional perspective (Table 1).

\subsubsection{Muscle Architecture}

Muscle architecture is defined as the macroscopic arrangement of muscle fibres within a muscle relative to the axis of force generation [8]. It has been previously described as the "structural property of the entire muscle that dominates its function" [8]. When the transducer is correctly aligned with the muscle fascicle plane, we can fully distinguish the orientation of fascicles relative to the transducer due to the presence of high contrast between connective and muscle tissue [10]. Thus, this correct alignment is essential for image quality as it takes advantage of the anisotropic nature of muscle. The length of the muscle fascicles (Lf) and the pennation angle (PA) (i.e., the angle formed by the insertion of the fascicle within the deep tendinous aponeurosis) (Fig. 1), represent the architectural parameters that can be detected by B-mode or EFOV US modalities (Fig. 2) [1, 12]. Lf and $\mathrm{PA}$, determined via B-mode US, are generally reliable and valid as shown in a systematic review by Kwah et al. [13].

Muscle architecture has previously been recognised as one of the primary determinants of muscle function [8]. Theoretically, $\mathrm{Lf}$ is dependent on the length and number of sarcomeres in series $[8,14,15]$, while PA is mostly seen as a strategy that allows more contractile material to be packed in along the deep aponeurosis of a muscle, seemingly reflecting the number of sarcomeres arranged in parallel $[6,16]$. Architectural characteristics can influence muscle force-length and force-velocity relationships [8, 9, 12]. Gans [16] and Lieber [8] explained theoretically that shorter muscle fibres present a lower maximum shortening velocity which likely would influence the velocity of contraction at the entire muscle level [12]. In contrast, the maximum force developed by a muscle is proportional to the number of sarcomeres in parallel, and thus to their PA [12]. However, despite these theoretical considerations, the reports showing a clear linear relationship between functional parameters and muscle architecture in-vivo are controversial, as we discuss in Sect. 3.1.

\subsubsection{Muscle Dimensions}

Muscle dimensions can be evaluated through linear, twodimensional, and volumetric indices. Muscle thickness (MT) represents the simplest and most employed measure of muscle dimensions, typically evaluated through B-mode US as the linear perpendicular distance between skeletal muscle interfaces (Fig. 1) [17]. The transducers can be placed transversally [18] or longitudinally $[6,17]$ in relation to the region of interest (ROI) chosen for a specific muscle or limb. MT has been shown to be reliable for different muscle groups $[17,19]$. US has also been employed to assess larger anatomical structures, such as muscle anatomical cross-sectional area (ACSA), whereby scans are acquired in the transversal plane (Fig. 3) [1]. ACSA scans can be obtained by the images-stitching technique [20] or by EFOV US imaging (i.e., panoramic US technique) [21]. EFOV has been shown to be a valid and reliable method for the assessment of quadriceps [22-24], gastrocnemius [24] and hamstrings $[25,26]$ ACSA when compared with magnetic resonance imaging (MRI) or computed tomography. In addition, the 
Fig. 1 Longitudinal B-mode ultrasound image of a human vastus lateralis muscle captured at $50 \%$ of the total femur length. Highlighted are the deep and superficial tendon aponeuroses and the most common features of muscle architecture: $M T$ muscle thickness, $L f$ fascicle length, $P A$ pennation angle. Image was obtained using a $4.7 \mathrm{~cm}$ linear transducer

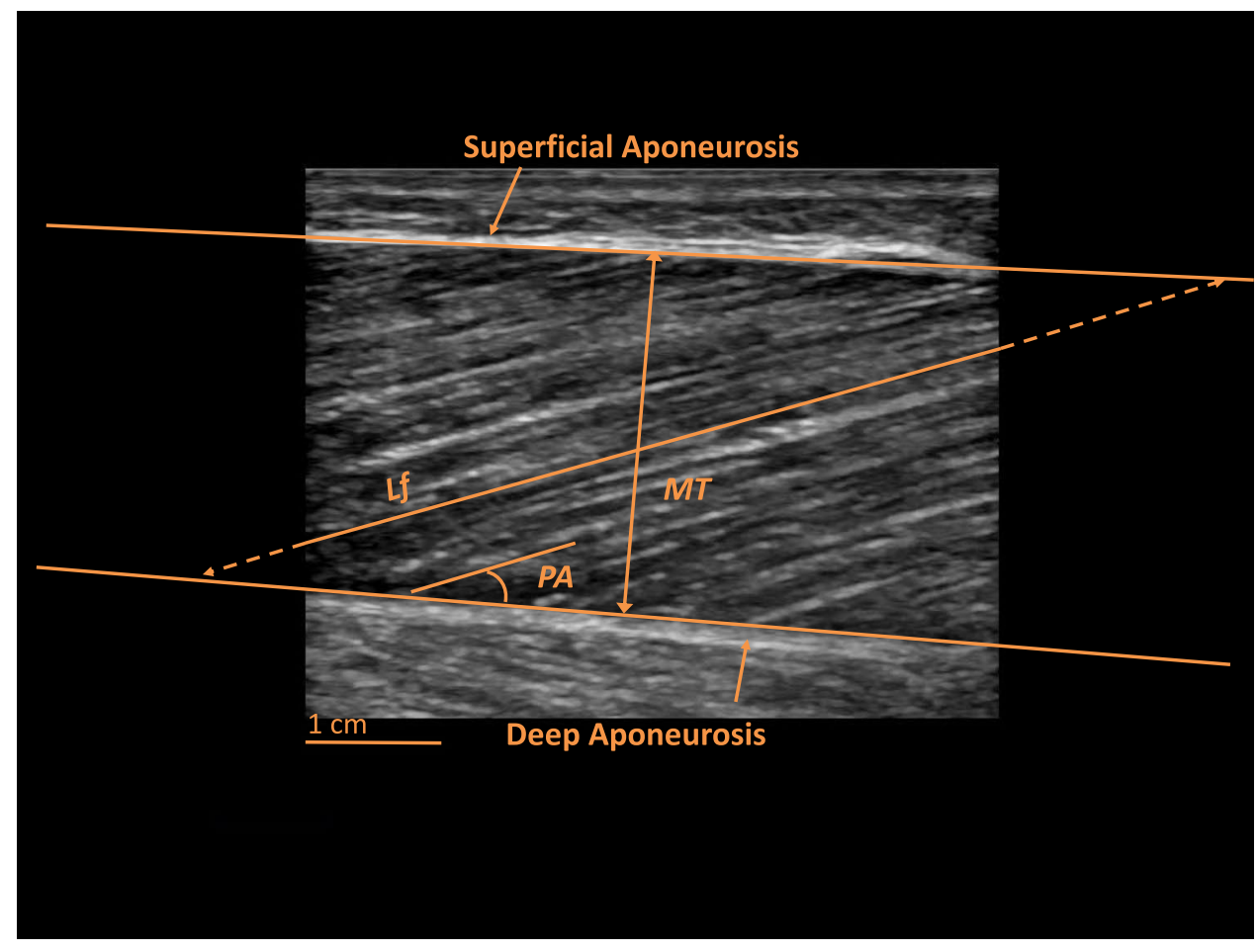

acquisition of an adequate number of ACSAs (generally 5-12 slices) at different portions of muscle length enables the estimation of muscle volume via different approaches [27]. Use of muscle volume has the advantage of accounting for regional differences in muscle dimension, of particular importance for the detection of resistance training-induced changes in muscle mass [17].

The evaluation of muscle dimensions may play a pivotal role in athletic performance or clinical settings. Indeed, muscle ACSA is strongly related to joint torque production and isokinetic strength in different muscle groups [28-30]. Similarly, muscle volume is considered one of the major determinants of joint torque in humans for both upper and lower limbs [31, 32].

\subsubsection{Muscle Quality}

In addition to measures of muscle morphology, estimation of muscle quality (based on tissue composition) can also be obtained by quantitative musculoskeletal US [33]. Echo intensity (or "echogenicity") is the measure of the reflectivity of sound waves reflected by the tissue. Echogenicity is considered a proxy of muscle composition and in turn it may be used as an index of muscle quality [33, 34]. Connective tissue and fat are more reflective than muscle tissue and thus appear in the image as lighter grey. The largest region of interest excluding aponeuroses is generally detected and then echo intensity measures are calculated as median grayscale values (a 0-255 scale of arbitrary units, with a higher value indicating more hyperechoic material) using programs such as ImageJ or Photoshop [35]. Low echo intensity values are considered to be associated with greater muscle quality; in contrast, high echo intensity values are thought to be related to muscle impairment [33]. US has been shown to be a reliable tool for the assessment of muscle quality as echo intensity in different populations [33], including young athletes [36]. Echo intensity has been mainly used to study muscle quality changes in aging [34], although attempts to apply it in a sports setting have been conducted [37-39].

\subsubsection{Tendon Dimensions}

Tendon dimensions are most commonly represented by tendon thickness and ACSA. Measurements of tendon thickness are typically obtained from longitudinal scans via B-mode in the resting state [40], whereas tendon ACSA can be measured from axial-plane US images taken at different portions of tendon length [41]. A recent review suggested that US measures of tendon dimensions are reliable, both in terms of relative and absolute reliability [42]. Tendon dimensions are related to the distribution of stress within the tendon itself, such that a greater tendon ACSA allows stress to be spread over a larger area and in turn enables greater force to be transmitted through the tissue [43]. 


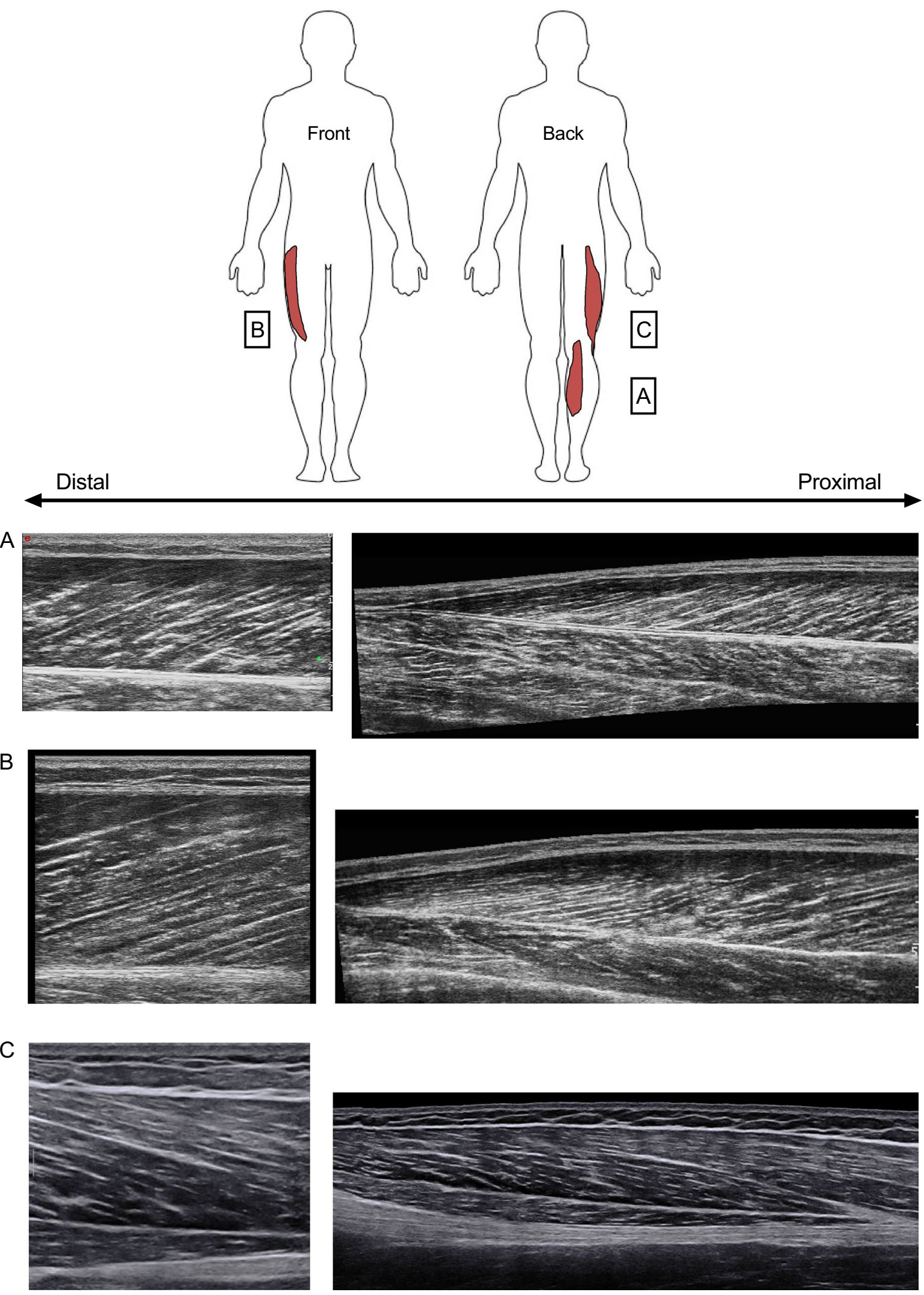


4Fig. 2 Longitudinal B-mode ultrasound snapshots and respective EFOV scans for three different muscles in young healthy volunteers: $A$ vastus lateralis, $B$ biceps femoris long head, $C$ gastrocnemius medialis. The arrows indicate the distal and proximal muscle portions. Images were obtained using a $4.7 \mathrm{~cm}$ linear transducer. EFOV extended-field-of-view ultrasound technique

\subsubsection{Tendon Mechanical Properties}

The biomechanical properties of tendinous tissues are related to the capacity and effectiveness of these tissues to transmit muscle force to the bone and thus enabling movement [44]. The determination of tendon mechanical properties in vivo has been estimated via the acquisition of force-elongation relationships, such that tendon stiffness is calculated as force divided by tendon elongation [5]. The combination of conventional B-mode US with isometric dynamometry enables the measurement of both tendon deformation (elongation) and force produced during a ramped isometric contraction (Fig. 4). In addition to tendon stiffness (or "elasticity"), other tendon mechanical properties such as strain, stress, Young's modulus, and hysteresis may be obtained [45]. Unsurprisingly, this non-invasive approach has been widely applied to study tendon plasticity in response to increased [41] or reduced [46] loading conditions, especially in consideration of the contribution of tendon biomechanical properties to rapid torque development [47].

\subsubsection{Muscle and Tendon Stiffness Measured with Elastography}

The recent introduction of SWE US for the assessment of muscle and tendon mechanical properties allows for the alternative quantifiable estimation of stiffness in the form of an elastogram (Fig. 5) [48, 49]. The most commonly used SWE technique is known as "super-sonic shear imaging" (SSI) [50]. Briefly, the basic principle of SWE is to create an acoustic radiation force impulse displaced in the underlying tissue, resulting in the propagation of a transient shear wave. The instantaneous shear wave velocity obtained (i.e., the calculation of the velocity by which the waves return to the transducer) is directly related to the elastic properties (i.e., shear modulus) of the tissue and can be mapped on an elastogram, which can be also be superimposed onto the B-mode US scan $[49,50]$. Similar to many US techniques, SWE is an operator-dependent method; however, when used by an expert operator, it is a reliable tool to evaluate the mechanical properties of different muscles at rest and during passive stretching [51]. Similarly, good reliability was found in the assessment of tendon properties [52].

Quantification of tissue shear modulus has biomechanical, physiological and clinical applications. For instance, muscle stiffness has been shown to be highly related to both active and passive forces and may be used in the near future to reliably estimate the force/torque produced by an individual muscle [50]. Muscle and tendon stiffness are likely to influence also joint mobility (i.e., range of motion) [53]. Moreover, SWE has been used to assess stiffness changes related to training, stretching, manual therapy, dry needling procedures, and injury [48, 49].

\section{Fields of Application in Elite Sports}

\subsection{Testing Athletes' Status with Respect to Performance-Related Factors and Their Response to Training}

Associations between parameters of muscle architecture/ dimensions and sports performance have been frequently observed within various athletic cohorts. Pioneering studies found significant negative correlations between vastus lateralis (VL) and gastrocnemius lateralis $\mathrm{Lf}$ and $100-\mathrm{m}$ personal best records in professional male and female sprinters $[54,55]$. Similarly, a positive relationship between VL and gastrocnemius lateralis Lf and sprint front crawl swimming performance was observed in young swimmers [56]. Interestingly, VL muscle architecture asymmetry (i.e., the percentage difference between limbs) has been reported to negatively influence jumping power and sprinting speed [37]. Indeed, a recent systematic review and meta-analysis showed an association between jump height with MT but not with lower-limbs muscle architecture [60]. Despite this, there are some studies reporting positive associations between jump height and muscle architecture in athletes belonging to different sports [57-59]. In contrast, a recent study observed a significant relationship between Achilles tendon stiffness and jumping height in children practising artistic gymnastic [61].

Similarly, measures of muscle dimensions have been associated with parameters related to sports performance. Adductors and hamstrings volume (assessed by MRI) [62] and knee extensors MT (medial side, evaluated by US) [63] correlated with sprint performance in highly trained sprinters. Furthermore, biceps femoris long head (BFlh) ACSA obtained by US was associated with $30 \mathrm{~m}$ sprint time in young elite football players [64]. VL volume was also found to be a strong predictor of ergometer performance (in a 2000-m time trial), sprint capacity and endurance capacity in Olympic rowers [65]. In long jumpers, ACSA of rectus abdominis (evaluated by MRI) was significantly correlated with long jump performance (i.e., personal long jump performance record) [66]. Significantly, a recent study observed that a larger soleus muscle (increased ACSA and volume) with a thicker Achilles tendon was associated with superior marathon performance [67]. Lastly, quadriceps ACSA 


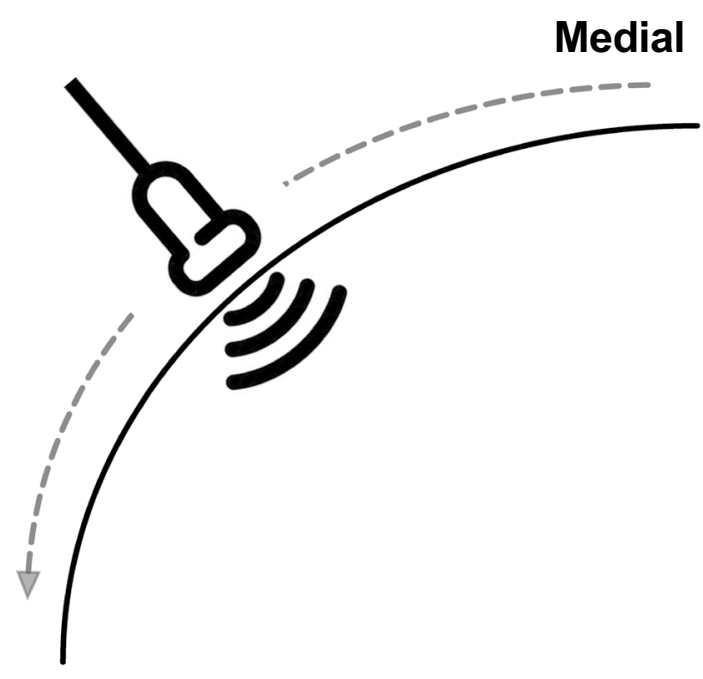

\section{Lateral}
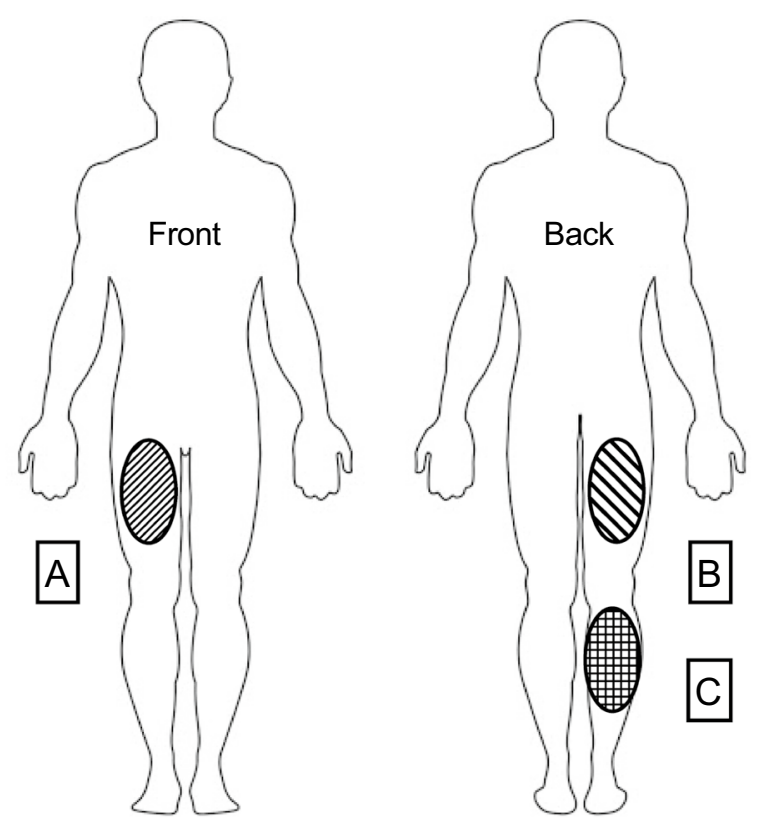

A

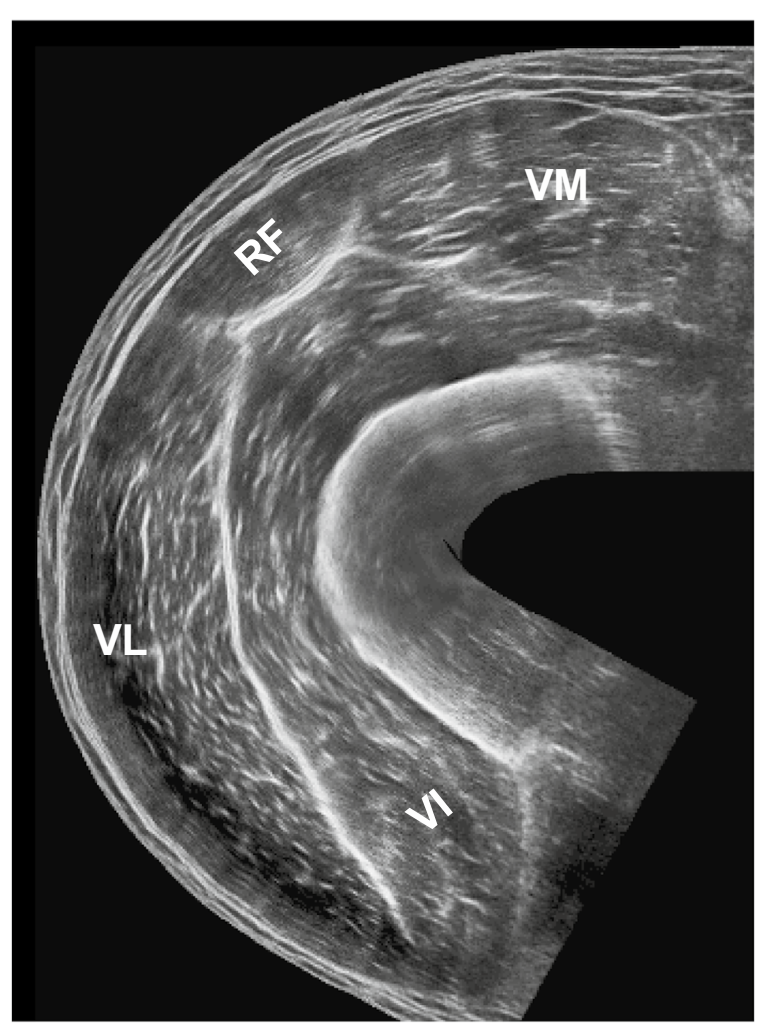

B

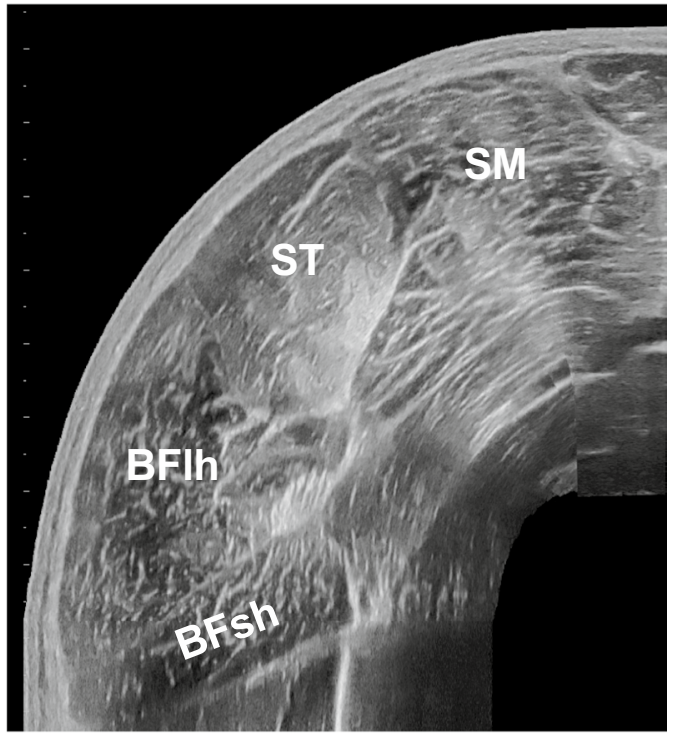

C

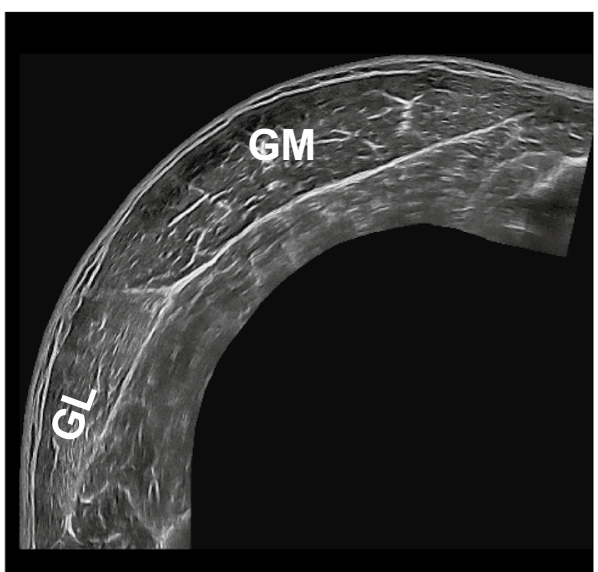


4Fig. 3 Transverse EFOV scans for three distinct muscle groups in young healthy volunteers: $A$ quadriceps femoris, $B$ hamstrings, $C$ triceps surae. Images were obtained using a $4.7 \mathrm{~cm}$ linear transducer. $E F O V$ extended-field-of-view ultrasound technique, $V M$ vastus medialis, $R F$ rectus femoris, $V L$ vastus lateralis, $V I$ vastus intermedius, $S M$ semimembranosus, $S T$ semitendinosus, BFlh Biceps Femoris long head, BFsh Biceps Femoris short head, $G M$ gastrocnemius medialis, $G L$ gastrocnemius lateralis

showed a robust correlation with weightlifting performance (i.e., maximum one repetition maximum in snatch and clean and jerk) in well-trained female weightlifters [68].

All the observations presented above have been made from cross-sectional studies, and it is important to stress that the reported associations do not provide evidence of causation. Nevertheless, such associations may help in generating potential causal structures that can be tested. Furthermore, in some longitudinal studies, the percentage changes in performance measures has been correlated with the percentage change in morphological musculoskeletal parameters. For example, in a study conducted in female softball players, strong relationships were found between changes in VL muscle architecture (MT and Lf) and changes in sport-specific sprint performance (i.e., time to reach first and second base) over a competitive season [69]. Similarly, young competitive throwers exhibited a significant correlation between the percentage increase in VL MT and percentage increase in a sport-specific throwing test (i.e., the shot put test from the power position), following a tailored-training program [59]. As aforementioned, while the above was of associational nature, these findings seem to support the plausibility of a causal relation.

Overall, associations between sports performance and parameters obtained via US have been consistently reported in such ecologically valid, albeit 'noisy' settings. These results should be considered with care, since studies conducted in more controlled laboratory settings demonstrate conflicting results. Indeed, in consideration of the relationships between functional parameters and muscle properties, some report robust associations [70] and others did not observe any [71].

Aside from their association with sports performance, muscle/tendon morphological and mechanical properties are known to be influenced by training. Thus, monitoring these properties over time can be beneficial in an elite sports scenario; namely for the assessment of an individual athlete response to a specific type of training, to the practice of their sport during a season, or throughout their sporting career. Indeed, measurements of training effects are important when monitoring the efficacy of the training stimulus provided to the athletes, and in turn, when controlling and adapting the training program [72]. For instance, it is well known that skeletal muscle hypertrophy occurs in response to strength $[14,73,74]$ and plyometric training [75]. Furthermore, different adaptations in muscle architecture [76] have been reported after eccentric [14, 77], concentric [14, 77], isometric [78], sprint [79], plyometric [75, 80] or combined (i.e., plyometric in addition to strength/power training) [81] training modalities. Structural (i.e., ACSA) and mechanical (i.e., stiffness) tendon properties are generally increased after loading interventions [82, 83]. In addition, the isolated practice of a specific sport can induce changes in muscle and tendon morphological and mechanical properties. Differences in muscle dimensions and architecture [84-88] as well as tendon features $[85,86,89,90]$ have been observed in cross-sectional studies comparing athletes practising different sports with non-athletes. Moreover, muscle architecture [91, 92], muscle stiffness [93], tendon stiffness and ACSA [94-96], and capacity to use tendon elastic energy [97] have been shown to differ in relation to chronic sportsspecific loading exposure. For the reasons listed above, US assessment has been implemented in longitudinal studies with the aim of investigating changes induced by sportsspecific practice during competitive seasons in athletes [69, $90,98]$ and/or to investigate the impact of tapering periods $[99,100]$. These evaluations may also be of particular interest in youth elite athletes to investigate the combined effects of sports practice and musculoskeletal growth on the functional and morphological development of muscle and tendon structures [101, 102].

\subsection{Detecting Athletes at Higher Risks of Injury}

It has been proposed that injury occurrence is regulated by a complex mechanical interplay between tissues stress, strain and loading [103]. It follows that alterations in muscle and tendon properties would play a fundamental role in injury processes. Thus, it is unsurprising that different US-derived measures of these parameters have been associated with injury risk in athletes of different sports. In an elite sport scenario, a periodic screening via US may help in estimating a potential risk factors for injury, if the methodological limitations of these studies are taken into account (i.e., lack of evidence of causality).

For instance, muscle Lf has been associated with muscle strain injuries. The theoretical rationale behind this association is that short muscle fascicles may present fewer inseries sarcomeres, and, therefore, may be more susceptible to the over-stretching experienced during powerful eccentric actions such as sprinting [104]. In particular, short biceps femoris long head (BFlh) fascicles have been proposed as a risk factor for hamstrings strain injuries in elite soccer players [104]. Similarly, a retrospective study showed that athletes with a previous hamstrings strain injury have shorter BFlh Lf in the limb with a history of injury than the contralateral uninjured limb [105]. Significantly, a major limitation of these investigations derives from the pitfalls of 


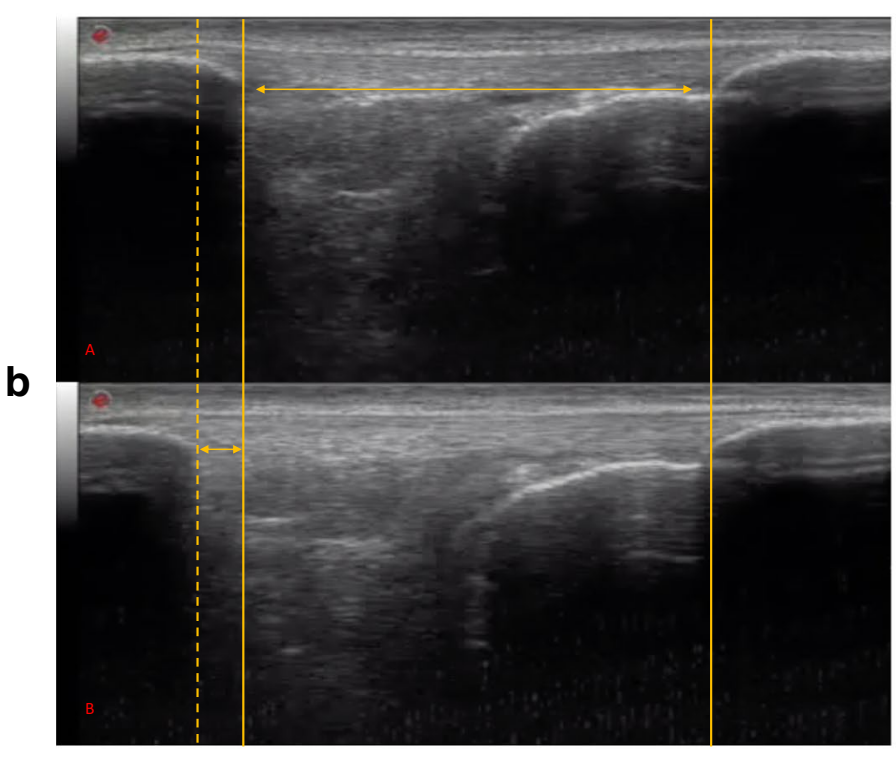

C

d
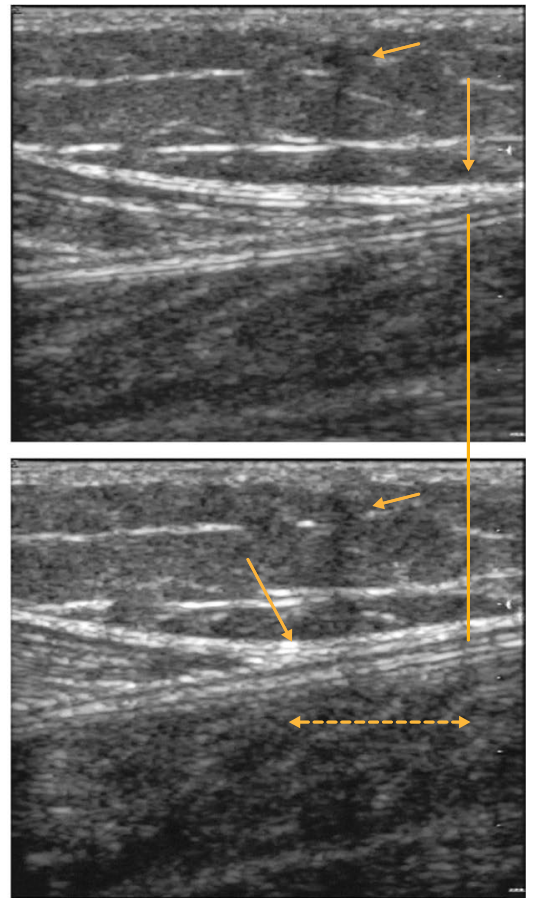

Fig. 4 Representative B-mode scans of patellar (a, b) and Achilles tendon $(\mathbf{c}, \mathbf{d})$. Images are obtained at rest $(\mathbf{a}-\mathbf{c})$ and during isometric ramp contractions (b-d). The solid lines demonstrate the resting tendon length for the patellar tendon $(\mathbf{a}, \mathbf{b})$ and where the gastrocnemius medialis myotendinous junction is/was situated $(\mathbf{c}, \mathbf{d})$. Dashed lines

linear extrapolation methods in the assessment of BFlh Lf, due to the limited field of view (FOV) employed that could have affected the results [106, 107] (the reader is referred to sect. 5.1.2). Therefore, future work should confirm this relationship using more appropriate US methods (e.g., EFOV) or other imaging techniques that would enable a thorough investigation of Lf, such as 3D US or diffusion tensor imaging (DTI).

Measurements of muscle dimensions appear to be related to musculoskeletal injuries. For instance, studies carried out in Australian Football League players have used measures of trunk muscle size to predict musculoskeletal injuries [108-111]. In particular, the ACSA of multifidus muscle [108-111] and the ratio between the ACSAs of the multifidus and quadratus lumborum muscles [111] were related to the occurrence of lower extremities injury both in the preseason and playing season. In a recent study conducted in young competitive alpine skiers, a smaller lumbar multifidus ACSA (assessed by MRI) was related to a higher occurrence of disc protrusions and end plate alterations [112]. Moreover, bilateral muscle differences in rectus femoris and VL ACSAs may be associated with games missed because of lower extremity injury in professional basketball players [38]. Based on the positive influence on maximal strength capacity [28-32], muscle dimensions measures assessed by show the respective elongation of each tendon. The arrows $\mathbf{c}, \mathbf{d}$ show the external marker (in this case a wire) that was applied on the skin as a reference. The bidirectional arrow with the broken line d indicates the Achilles tendon displacement. Images were obtained using a $4.7 \mathrm{~cm}$ linear transducer

US can integrate muscle strength measures for the detection of subjects at higher injury risk. For instance, associations between muscle size, hamstrings-to-quadriceps ratio, and the hamstring-to-quadriceps strength ratio have been reported previously [28].

\subsection{Screening the Athlete for Structural Abnormalities Related to Current or Future Musculoskeletal Complaints}

Traditional US and US-based SWE have been adopted as diagnostic tools for the evaluation of tendinopathies, tendon injuries, and ruptures [52]. Indeed, an increased ACSA is generally observed in injured tendons, likely due to an increase in water content alongside hypervascularization [82]. A reduced stiffness pattern evaluated by SWE has been found in pathological Achilles [113-115], patellar [116, 117] and rotator cuff tendons [118, 119]. Similarly, muscle stiffness, related to muscle activity and joint mobility, can be linked to tendinopathy. For example, an increased stiffness of the upper trapezius muscle [120] and a decreased stiffness of the deltoid muscle [121] are associated with rotator cuff tendinopathy. SWE and US may be also useful for the early detection of subclinical tendinopathies, providing additional time for the implementation of conservative measures [52]. 
A
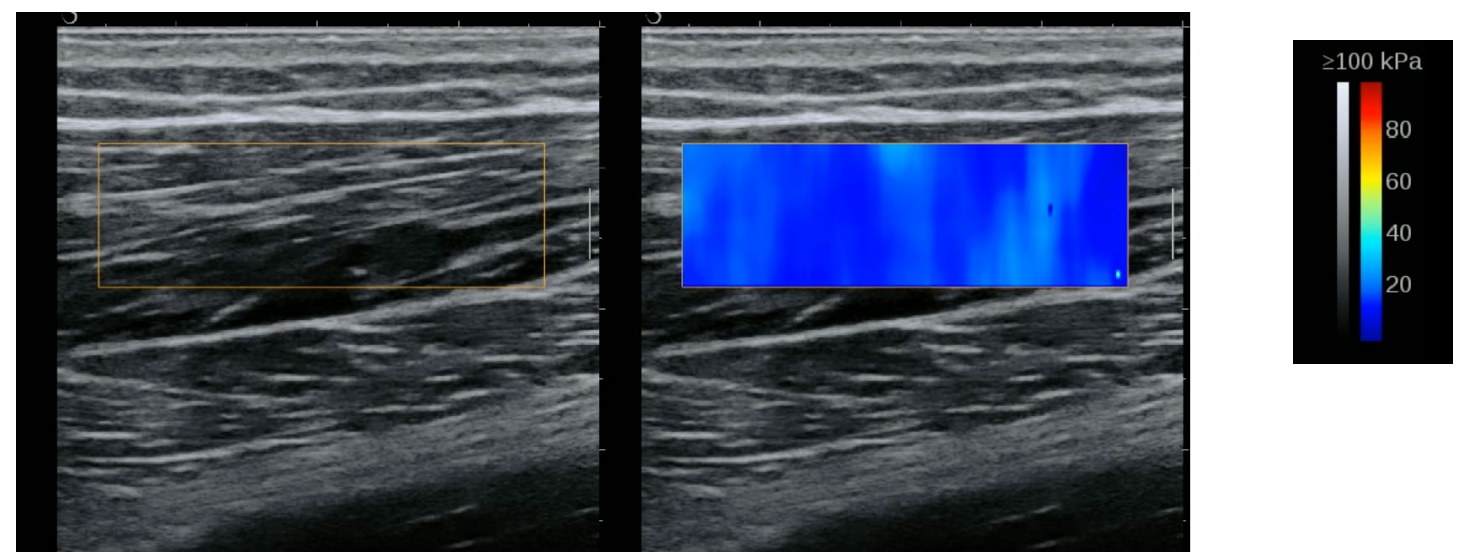

B
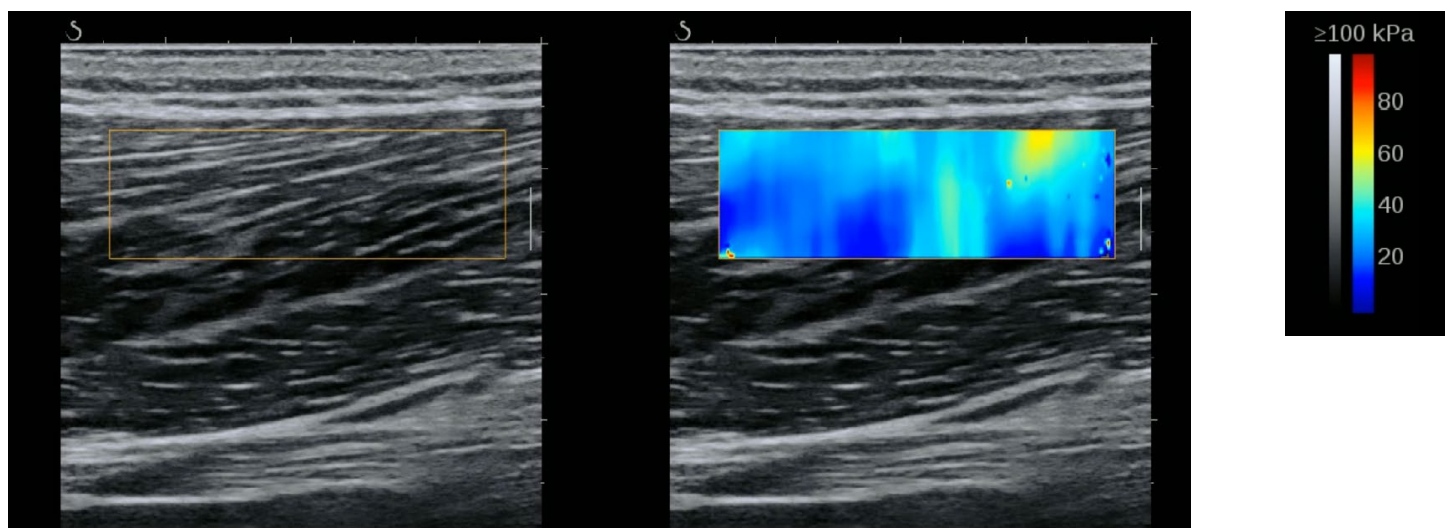

Fig. 5 Representative shear wave elastography scan acquired from the biceps femoris long head muscle of two different young healthy volunteers (a, b). The shear wave modulus elastogram is presented

Several studies of athletes participating in different sports have shown that tendon softening (i.e., reduced stiffness), detected with SWE, may explain current (and predict future) tendon pain and tendinopathy [116, 122-124].

Several studies have investigated the relationship between lumbar muscle characteristics and low back pain. It has been observed that multifidus ACSA is negatively associated with and predictive of low back pain for up to 12 months in different populations, including athletes [125]. Similarly, paraspinal muscles ACSA was found to predict low back disability (but not pain intensity) in people with low back pain of 2-12 month duration [126]. Other reports show that lumbar muscle stiffness differ in individuals with low back pain compared with asymptomatic controls [127, 128]. Moreover, swimmers with low back pain exhibited higher stiffness of the psoas major and lower stiffness of pectoralis minor compared to a control group [129]. next to the two scans, indicating an increased stiffness for subject B. Images were obtained using a $5 \mathrm{~cm}$ linear transducer

\subsection{Monitoring the Return to Sport After a Musculoskeletal Injury}

Loss of muscle structure and function may occur after musculoskeletal injuries and/or post-surgery situations mainly due to the disuse and/or detraining experienced [130, 131]. Therefore, monitoring the change in US-derived parameters allows more specific insight into the actual status of athletes during their return to sport. For instance, muscle ACSA and volume have been assessed in athletes and patients recovering from anterior cruciate ligament reconstruction [132-135] or hamstrings strain injury [136-138]. Such evaluation can be helpful also to examine the effectiveness of rehabilitation programs on muscle morphological outcomes, when comparing them to pre-injury measures [139]. In addition, since muscle architecture is known to be affected by musculoskeletal injuries [105, 140,141], US can be used to characterize the behaviour of fasicles and PA during the return to sport using pre-injury measures or the contralateral uninjured limb as reference. For instance, after Achilles tendon ruptures, and for the following 2-4 weeks, the injured limb presents 
altered medial gastrocnemius architecture (shorter Lf and greater PA) compared to the gastrocnemius in the uninjured limb [140]. A representative EFOV transverse scan of the quadriceps muscle group of a subject who suffered a previous muscle injury is presented in Fig. 6.

\section{Methodological Considerations}

\subsection{Muscle Ultrasound}

\subsubsection{Muscle Architecture Assessment}

The reflection of the acoustic waves is dependent on the orientation of the transducer (i.e., the direction of travel of the sound waves) relative to the position of the underlying tissue [2]. The optimum 'angle of incidence' (i.e., the angle at which the sound waves meet the surface of the scanned tissue) is located when the direction of the structure is nearly perpendicular to the direction of motion of the acoustic waves [2]. Thus, during the acquisition of longitudinal scans for the evaluation of muscle architecture, it is crucial to carefully align the transducer with the muscle fascicle plane [1]. For the methodological considerations related to manual digitalization variability and the size of the FOV employed in the assessment of muscle architecture properties, we refer the reader to the sections ' 5.1 .4 ' and '5.1.2', respectively.

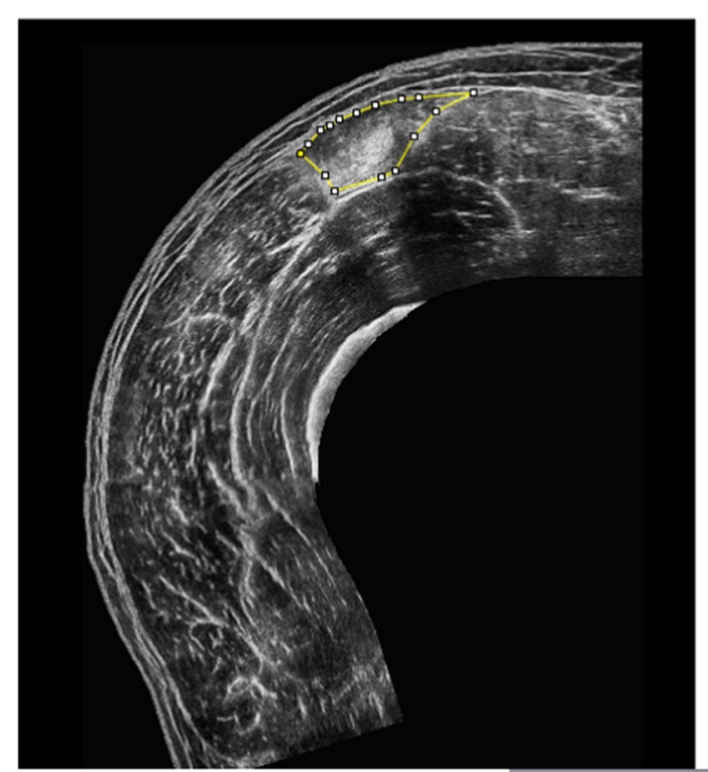

Previously injured

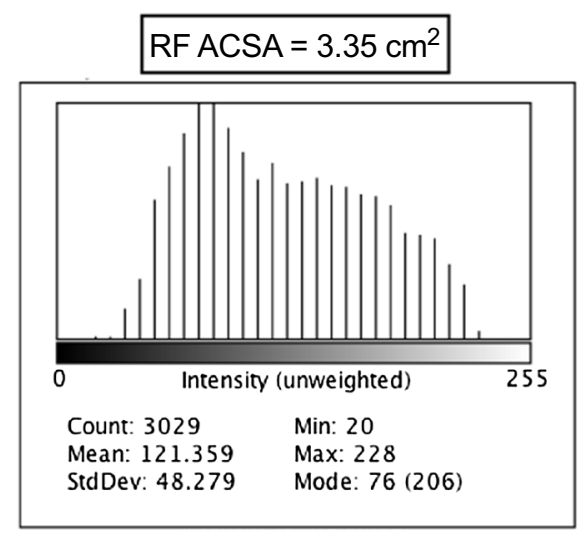

Fig. 6 Panoramic scans of right and left quadriceps femoris muscle of a young volunteer who previously sustained a RF muscle injury. Respective RF muscles contours and areas are shown for the previously injured and healthy legs, together with the histogram analyses
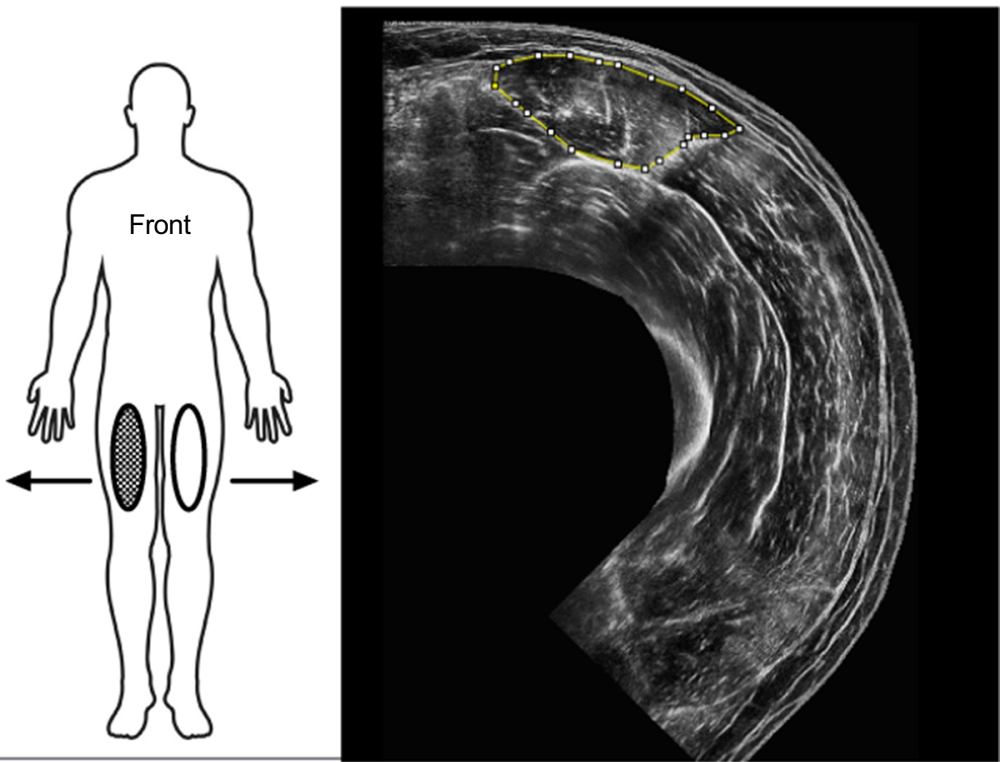

Healthy

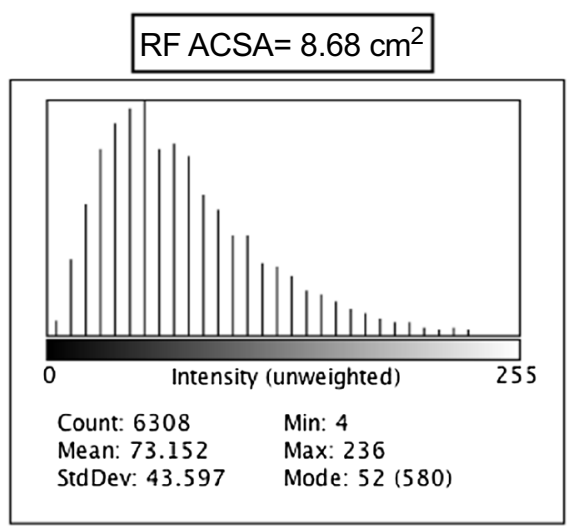

of echo-intensity (expressed in arbitrary units), suggesting decreased muscle quality in the previously injured leg. Images were obtained using a $4.7 \mathrm{~cm}$ linear transducer. $R F$ rectus femoris, $A C S A$ anatomical cross-sectional area, StdDev standard deviation 


\subsubsection{Muscle Thickness Assessment}

The principal methodological consideration in the assessment of MT is related to the pressure exerted by the operator on the skin and the underlying tissue, which in turn would influence the measurement. As muscle tissue can be deformed, excessive transducer pressure applied by the operator will result in lower MT values. Transmission gel should be used to improve the acoustic contact and to reduce the transducer pressure on the skin.

As previously explained, MT can be evaluated by placing the transducer both transversally [18] or longitudinally $[6,17]$ with respect to the scanned limb. In our experience, utilising the longitudinal scan to evaluate MT is the better of the two. In transversal scans, muscle borders are curved and thus the evaluation of MT would be entirely dependent on where MT is measured (i.e., between which specific points), thus being more difficult to standardize. Conversely, if the image is correctly acquired in longitudinal scans, the aponeuroses should be parallel (at least in scans performed in the middle of muscle belly, the ROI where MT is usually assessed) and thus the MT will be represented by a simple linear distance between two linear borders. We, therefore, suggest obtaining MT and muscle architecture from the same image to achieve a measure of muscle dimension in relation to the fascicle arrangement analysed. MT values are generally obtained by averaging three measurements across the proximal, central, and distal portions of the acquired image [17].

\subsection{Tendon Ultrasound}

\subsubsection{Assessment of Tendon Mechanical Properties}

The assessment of tendon mechanical properties is one of the most challenging to implement in a sports scenario, due to several methodological and technical aspects to consider. For an extensive and critical evaluation of the US-based testing of tendon mechanical properties, we refer the reader to Seynnes et al. [45]. However, we will briefly describe some of the possible sources of error below.

The US-based evaluation of tendon mechanical properties are also restricted by narrow FOV. As such it can be challenging to scan both proximal and distal extremities of the tendon simultaneously, an issue which can significantly improve data accuracy. Nonetheless, the use of a longer transducer and the adjustment of transducer orientation to account for the three-dimensional behaviour of tendon deformation can overcome this issue [45]. The acquisition of both extremities enables the use of automated tracking or at the very least semi-automated, which should always be employed to reduce manual intervention variability and operator bias. The use of both tendon insertion points as opposed to related structures such as aponeuroses is strongly recommended [45]. In addition to decreased variability, automated tracking may reduce processing time. To acquire an accurate estimation of tendon force, both internal and external moment arms should be measured individually. Moreover, subjects should be trained to reduce co-contractions and to increase or decrease moment production linearly at a target rate [45]. In addition, subjects should complete preconditioning of the tendon prior to assessment via a minimum of five submaximal contractions [142]. Finally, data acquisition should have high temporal and spatial resolution and should be centralized into a single software. Absence of image lag when acquiring other signals synchronously should be achieved [45].

\section{General Issues}

\subsection{Echo intensity Assessment}

Echo intensity values rely on grayscale analysis (Fig. 6). For this reason, US settings (e.g., brightness, contrast, number and position of foci, persistence and special views) must be kept consistent between pre- and post-measurements. For the same reason, post-processing scan modifications (e.g., brightness, contrast, colour balance/threshold) should not be applied during analysis.

While some reports support the use of echo intensity as a marker for muscle quality in different interventions [143, 144], in our experience echo intensity measures do not show great sensitivity for changes in muscle quality after training or unloading periods in young subjects (unpublished data). In support of this notion, echo intensity response to chronic exercise training is controversial in young subjects, while decreases in echo intensity seem to be consistent in older adults [33]. Moreover, echo intensity has been shown to change at the presentation of a serious injury (Achilles tendon rupture), but was not different when compared to the contralateral muscle after 2 and 4 week post-injury [140]. Thus, we recommend a careful approach when using this proxy for muscle quality in athletes.

\subsubsection{Shear Wave Elastography}

SWE systems are built on the assumption that the analysed soft tissues are completely elastic, incompressible and isotropic (i.e., obtained values are independent from the direction of measurement). However, muscles and tendon exhibit an anisotropic behaviour. Indeed, it has been observed that shear waves travel at a higher velocity along the direction of the fibres compared to transversally to them $[145,146]$. It is, therefore, essential to standardize the transducer's position, 
so that it is aligned with the orientation of muscle or tendon fibres $[48,49]$.

Other factors such as transducer pressure, ROI sizes and scan acquisition time can also influence SWE stiffness outcomes [147]. SWE acquisitions on muscle and tendon should be performed with the lightest transducer pressure, a shorter acquisition time, maintaining constant ROI size [147]. In addition, the propagation of the shear waves is attenuated at greater acquisition and is thus dependent on surrounding tissues (e.g., thick superficial fat layers) [48].

\subsubsection{B-Mode vs. EFOV}

The main limitation of standard B-mode US is the relatively small FOV, which is determined by the size of the transducer [1]. The length of the commercially available transducers is typically $4-5 \mathrm{~cm}$, although it may be as large as $10 \mathrm{~cm}$ in some devices. Shorter transducers with higher temporal resolution (i.e., acquisition frame rate) are ideal for the study of muscles with short Lf (e.g., triceps surae muscle group). However, a limited FOV can affect the results for Lf values of muscles that have longer fascicles and more complex fascicle arrangement (e.g., quadriceps femoris muscle group) $[19,106]$. In these circumstances, longer transducers are advised for the evaluation of muscle architecture.

If only conventional B-mode is available, Lf can be estimated using extrapolation methods [148, 149]. Aside from the manual linear extrapolation method, one possible approach is represented by a trigonometric equation [148], in which the Lf estimation is based on MT, PA and the angle between the aponeuroses. While this technique makes the analysis less time consuming and thus suitable for an elite sport context, it neglects fascicle and aponeuroses curvature. Therefore, this techniques seems inaccurate for muscles with a non-homogeneous architecture along their length and concave/convex fascicle (e.g., BFlh) [106].

The EFOV technique allows for the study of larger anatomical structures, thus representing a good strategy to overcome the limitation of a restricted FOV of the transducer for the assessment of muscle architecture. This technique is based on texture mapping algorithms that stitch together sequences of images collected during scanning to reconstruct a unique combined panoramic image [21]. EFOV can be used to evaluate both ACSA (performing a transverse scan) and muscle architecture (performing a longitudinal scan) [1]. Longitudinal EFOV scans, compared to B-mode US, have the clear advantage of providing larger images, where no extrapolation is required to assess Lf. This is of particular importance for muscles with long fascicles and where the architectural arrangement changes between different portions of muscle length [148]. On the other hand, one major limitation is the difficulty of keeping the transducer aligned to the fascicle plane throughout whole muscle scans [19]. Transversal EFOV scans include potential limitations such as the pressure applied on the skin by the operator (as explained also in sect. 4.1.2) and in the employment of linear transducers for the assessment of curved surfaces [1]. It is worth noting, however, that not all US devices enable the possibility to perform EFOV scans.

Others technique that obtain larger FOV images, such as dual probe technique (i.e., the use of two linear transducers placed in series) [150] and 3D US [151], have been proposed and employed in a laboratory setting. However, in elite sports scenarios these techniques are difficult to implement due to the need of further expensive instruments (e.g., motion capture systems, more transducers) and algorithms for data analysis and processing.

\subsubsection{Static vs. Dynamic US}

Most US measurements have generally been acquired in resting conditions. However, over the past few decades US has been used also to study muscle and tendon behaviour during dynamic movements $[2,10,11]$. In particular, PA and fascicle, tendon and aponeurosis length changes have been evaluated both during muscle contraction and passive joint movement [10]. B-mode US seems to be a reliable method to evaluate muscle architecture during movement [11].

Since every sports activity is characterized by a combination of movements, and musculoskeletal injuries generally occur during dynamic contractions; these measures obtained by dynamic US might be potentially more informative when employed in a sports context. However, several technical considerations that limit the use of dynamic US in an applied sports setting should be considered. First, dynamic conditions require the transducer to be completely fixed to the limb scanned and this procedure necessarily results in compression of the underlying structures [10]. Secondly, the operators should strive to maintain a consistent alignment of the image plane with the fascicle plane. Indeed, errors in fascicle length measurements due to transducer malalignment issues can reach $20 \%$ [152, 153]. The best estimate of muscle architecture seems to be obtained keeping the transducers perpendicular to the skin, at least for gastrocnemius medialis muscle $[152,153]$. Whether this alignment is always maintained during a dynamic movement is difficult to determine [2]. Such alignment must be chosen with care as it is known that muscle fascicles arrangement changes with contraction, and so does the shape of the muscle itself. Thus, the best alignment between the transducer and the fascicle plane can be seen as a trade-off between transducer fixation and changes of muscle geometry and shape due to 
contraction. Furthermore, the visibility of muscle and tendon in their entire length is essential in dynamic conditions, but the limitations related to a restricted FOV are present as discussed for the static condition (see sect. 5.1.2). This is particularly important as muscle and tendon length changes in a small region of interest do not necessarily mirror the behaviour in other regions of the muscle [10]. This limits the number and/or size of the muscles and tendons that can be imaged with this technique [2]. The frame rate (i.e., how many images the US device can acquire in one second) is another important parameter to consider when acquiring dynamic US scans. Indeed, for fast dynamic tasks (i.e., high speed running, jumping, and landing) a high temporal resolution is necessary. Finally, despite the application of automatized feature-tracking algorithms, data analysis may be more complex for dynamic compared to static conditions.

All these factors can be reasonably controlled in laboratory settings if all the recommendations to improve the reliability and validity of dynamic US are followed [11]. However, in a sports context, where time and equipment are often limited, its application may be very challenging. Thus, we believe that teams and sports federations willing to implement US with athletes should focus mainly on static measures until technological advances in dynamic US have been achieved.

\subsubsection{Operators and Raters Experience}

Acquisition of US scans is known to be an operator-dependent procedure. In particular, EFOV scans are more difficult to acquire compared to B-mode US scans, primarily due to the challenge of keeping the transducer parallel to the fascicle plane over a large area of interest [154]. Extensive operator training is, therefore, essential to ensure reliability and to manage all the discussed technical issues (e.g., probe alignment and transducer pressure). For novice operators, we suggest performing a calculation of the repeatability of the measurements (via interclass correlation coefficient and coefficient of variation [CV] of the standard error mean) and the minimal detectable change (MDC, i.e., the minimum difference suggesting a real change, which would not be subjected to repeated measurement errors) before collecting data. Because CVs and MDCs could differ between different muscles, care should be taken in the calculation of such parameters for each US technique and US-based measurement. Sports teams and federations interested in implementing US imaging in an elite sports context should consider the introduction of a specialized individual (a sonographer or a sports scientist/sports medicine specialist with expertise in musculoskeletal imaging) to the staff.
In addition, manual data analysis can be influenced by operator's experience, specifically the variability related to manual digitalization process. For instance, in a recent study, Franchi et al. found worse agreement between US and MRI values for a completely novice rater compared to a trained rater in the assessment of individual hamstring muscle ACSAs [26]. Interestingly, this agreement was found to improve for the trained rater after manual analysis of MRI scans, highlighting the importance of operator's training also for data analysis [26]. Due to the impact of operator's experience and the time requirement to gain this, attempts have been made to automate this data analysis process. In particular, an ImageJ macro tool to automate measurements in B-mode US scans called 'Simple Muscle Architecture Analysis' (SMA) has recently been proposed by Seynnes \& Cronin [155]. From this preliminary study, this automated analysis seems to not induce any systematic bias when compared to manual analysis [155]. Therefore, this tool seems to be a promising approach to analyse images from superficial muscles in an objective and less time consuming way. However, SMA relies on muscle fascicle orientation, and thus may be not yet appropriate for muscles that present complex and variable muscle architecture arrangement (e.g., BLFlh). To date, no automatized analysis for EFOV images (both for longitudinal and transverse scans) is available.

Although different scanners enable the measurement of US parameters on the machine itself, it is more usual to perform the analysis off-line. Based on our experience, we believe that this second approach makes the analysis more accurate as it allows image modifications post -acquisition, thus facilitating various analyses. Moreover, off-line analysis represents the only solution if the fascicle is not fully visible. Ultimately, since most of the analysis in previous works was conducted using the same software (ImageJ), this can lead to an improved standardization of such analyses within the scientific community.

\section{Future Directions}

The morphological and mechanical properties of muscle and tendon are associated with functional and sports performance. Indeed, they play an important role in testing the response to training, detecting athletes at higher risks of injury, screening athletes for structural abnormalities related to current or future musculoskeletal complaints and monitoring their return to sport after a musculoskeletal injury (Table 1). Despite the well-known problems related to the interpretation of associations suggesting the potential effect of confounders; the results of previous observational studies seem to support the plausibility of a causal link. Thus, 
Table 1 Principal US-based measures of muscle and tendon morphological and mechanical properties, their functional significance and application in sports scenarios, and associated methodological considerations

\begin{tabular}{|c|c|c|c|}
\hline Parameter & Functional significance & Application in sports scenarios & Methodological considerations \\
\hline Muscle Architecture (Lf; PA) & $\begin{array}{l}\text { Lf is related to velocity of contrac- } \\
\text { tion } \\
\text { PA is related to maximal force } \\
\text { production }\end{array}$ & $\begin{array}{l}\text { Monitoring of athletes' status } \\
\text { Detection of athletes at potential } \\
\text { higher injury risk (short Lf) }\end{array}$ & $\begin{array}{l}\text { Transducer alignment } \\
\text { Manual digitalization variability } \\
\text { Field of view employed } \\
\text { Operator's experience } \\
\text { (in particular for the acquisition of } \\
\text { EFOV scans) }\end{array}$ \\
\hline $\begin{array}{l}\text { Muscle dimensions (MT; ACSA; } \\
\text { volume) }\end{array}$ & $\begin{array}{l}\text { Related to joint torque production } \\
\text { and isokinetic strength }\end{array}$ & $\begin{array}{l}\text { Monitoring of athletes' status } \\
\text { Detection of athletes at higher } \\
\text { injury risk (reduced muscle size) }\end{array}$ & $\begin{array}{l}\text { Transducer pressure } \\
\text { Longitudinal vs. transverse scan } \\
\text { for MT assessment } \\
\text { Operator's experience } \\
\text { (in particular for the acquisition of } \\
\text { EFOV scans) }\end{array}$ \\
\hline Muscle quality (echo intensity) & $\begin{array}{l}\text { Proxy for muscle quality/composi- } \\
\text { tion }\end{array}$ & $\begin{array}{l}\text { Evaluation of potential alteration } \\
\text { post-injury and during the return } \\
\text { to sports journey }\end{array}$ & $\begin{array}{l}\text { Maintenance of the same US } \\
\text { setting } \\
\text { Avoidance of post-processing } \\
\text { analysis application } \\
\text { Limited sensitivity in changes }\end{array}$ \\
\hline $\begin{array}{l}\text { Tendon dimensions (thickness; } \\
\text { ACSA) }\end{array}$ & $\begin{array}{l}\text { Related to the distribution of stress } \\
\text { within the tendon }\end{array}$ & $\begin{array}{l}\text { Detection and evaluation of tendi- } \\
\text { nopathy }\end{array}$ & Operator's experience \\
\hline $\begin{array}{l}\text { Tendon mechanical properties } \\
\text { (stiffness; strain; stress) }\end{array}$ & $\begin{array}{l}\text { Related to the capacity to transmit } \\
\text { muscle force to the bone }\end{array}$ & $\begin{array}{l}\text { Monitoring of athletes' status } \\
\text { Detection of tendinopathy }\end{array}$ & $\begin{array}{l}\text { Scanning issues } \\
\text { Tracking issues } \\
\text { Estimation of tendon force } \\
\text { Signal synchronization }\end{array}$ \\
\hline $\begin{array}{l}\text { Muscle and tendon stiffness meas- } \\
\text { ured with SWE }\end{array}$ & $\begin{array}{l}\text { Related to force production and to } \\
\text { the capacity to transmit muscle } \\
\text { force to the bone }\end{array}$ & $\begin{array}{l}\text { Monitoring of athletes' status } \\
\text { Indirect assessment of muscle } \\
\text { force and joint mobility } \\
\text { Detection and evaluation of mus- } \\
\text { culoskeletal complaints }\end{array}$ & $\begin{array}{l}\text { Anisotropic physical properties of } \\
\text { skeletal muscle } \\
\text { Management of technical factors } \\
\text { (transducer pressure; region of } \\
\text { interest size; scan acquisition } \\
\text { time; acquisition depth) }\end{array}$ \\
\hline
\end{tabular}

$M T$ muscle thickness, $L f$ fascicle length, $P A$ pennation angle, $S W E$ shear wave elastography, $E F O V$ extended-field-of-view

regular assessment of these parameters may provide important information for sports practitioners and medical staff working alongside athletes. However, while US provides a non-invasive evaluation of these characteristics, many practical and methodological recommendations should be considered for its implementation in an elite sports scenario. Since extensive training and experience are required for US scan acquisition and analysis, we believe that a new specialized figure in musculoskeletal imaging (a sonographer or a sports scientist with expertise in US) should be introduced (or trained) in teams/federations interested in implementing this technique. Future research should focus on designing new tools for data processing and analysis, with the aim to give real time feedback to the staff and make it less time consuming and more objective (i.e., less dependent on operator's experience). Automatized programs for the assessment of muscle ACSA and EFOV scans should be developed.
Furthermore, appropriate designs and analysis are warranted to understand the prognostic ability of these measures.

\section{Conclusion}

US may have many promising application areas in an elite sports scenario. However, the practical issues and methodological considerations elaborated in this review should be considered when striving to provide valid and relevant information for benefiting athletes' performance enhancement or for health protection. Moreover, this review may have re-scoped the agenda of potential future research directions in connection with implementing US imaging for the assessment of muscle and tendon properties in elite sports (Fig. 7). 


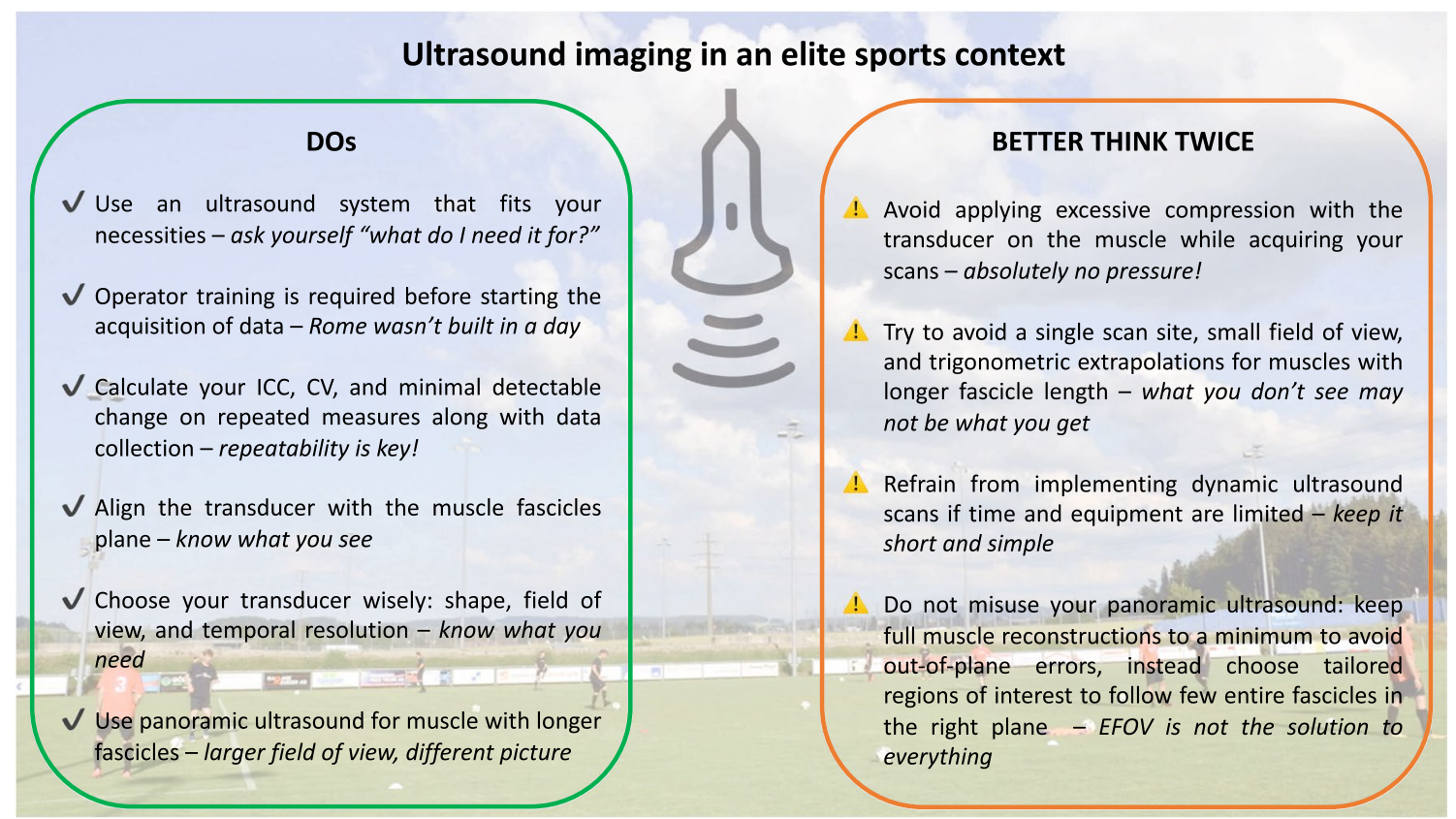

Fig. 7 Panel of practical recommendations for the implementation of ultrasound-based imaging in the elite sports context. ICC intraclass correlation coefficient, $C V$ coefficient of variation, $E F O V$ extended-field-of-view ultrasound technique

Acknowledgements Imaging was partially performed with equipment maintained by the Swiss Center for Musculoskeletal Imaging, SCMI, Balgrist Campus AG, Zürich, to which the authors are particularly grateful. The authors would also like to thank Professor Franco Impellizzeri for his precious comments and suggestions regarding our manuscript.

Author contributions FS, JS and MVF designed and conceptualized the review. FS, JS and MVF wrote the initial draft. DPF, JIQ and MVN revised the draft. All authors contributed to the manuscript and approved the final version.

Funding Open access funding provided by Università degli Studi di Padova within the CRUI-CARE Agreement.

\section{Declarations}

Funding This review was generously supported by the Balgrist Foundation. No other sources of funding were used to assist in the preparation of this article.

Conflict of interest Fabio Sarto, Jörg Spörri, Daniel Fitze, Jonathan Quinlan, Marco Narici and Martino Franchi declare that they have no conflicts of interest relevant to the content of this review.

Open Access This article is licensed under a Creative Commons Attribution 4.0 International License, which permits use, sharing, adaptation, distribution and reproduction in any medium or format, as long as you give appropriate credit to the original author(s) and the source, provide a link to the Creative Commons licence, and indicate if changes were made. The images or other third party material in this article are included in the article's Creative Commons licence, unless indicated otherwise in a credit line to the material. If material is not included in the article's Creative Commons licence and your intended use is not permitted by statutory regulation or exceeds the permitted use, you will need to obtain permission directly from the copyright holder. To view a copy of this licence, visit http://creativecommons.org/licenses/by/4.0/.

\section{References}

1. Franchi MV, Raiteri B, Longo S, Sinha S, Narici MV, Csapo R. Muscle architecture assessment: strengths, shortcomings and new frontiers of in vivo imaging techniques. Ultrasound Med Biol. 2018;44:2492-504.

2. Lichtwark G. Ultrasound technology for examining the mechanics of the muscle, tendon, and ligament. In: Muller B, Wolf SI, Brueggemann GP, Deng Z, McIntosh A, Miller F, Selbie WS, editors. Handbook of human motion. Cham: Springer; 2017. p. $1-20$.

3. Ikai M, Fukunaga T. Calculation of muscle strength per unit cross-sectional area of human muscle by means of ultrasonic measurement. Int Zeitschrift für Angew Physiol Einschließlich Arbeitsphysiologie. 1968;26:26-32.

4. Narici MV, Binzoni T, Hiltbrand E, Fasel J, Terrier F, Cerretelli $P$. In vivo human gastrocnemius architecture with changing joint angle at rest and during graded isometric contraction. J Physiol. 1996;496:287-97.

5. Fukashiro S, Rob M, Ichinose Y, Kawakami Y, Fukunaga T. Ultrasonography gives directly but noninvasively elastic characteristic of human tendon in vivo. Eur J Appl Physiol Occup Physiol. 1995;71:555-7.

6. Kawakami Y, Abe T, Fukunaga T. Muscle-fiber pennation angles are greater in hypertrophied than in normal muscles. J Appl Physiol. 1993;74:2740-4. 
7. Rutherford OM, Jones DA. Measurement of fibre pennation using ultrasound in the human quadriceps in vivo. Eur J Appl Physiol Occup Physiol. 1992;65:433-7.

8. Lieber RL, Fridén J. Functional and clinical significance of muscle architecture. Muscle Nerve. 2000;23:1647-66.

9. Narici MV. Human skeletal muscle architecture studied in vivo by non-invasive imaging techniques: Functional significance and applications. J Electromyogr Kinesiol. 1999;9:97-103.

10. Cronin NJ, Lichtwark G. The use of ultrasound to study muscletendon function in human posture and locomotion. Gait Posture. 2013;37:305-12.

11. Van Hooren B, Teratsias P, Hodson-Tole EF. Ultrasound imaging to assess skeletal muscle architecture during movements: a systematic review of methods, reliability, and challenges. J Appl Physiol. 2020;128:978-99.

12. Narici M, Franchi M, Maganaris C. Muscle structural assembly and functional consequences. J Exp Biol. 2016;219:276-84.

13. Kwah LK, Pinto RZ, Diong J, Herbert RD. Reliability and validity of ultrasound measurements of muscle fascicle length and pennation in humans: a systematic review. J Appl Physiol. 2013;114:761-9.

14. Franchi MV, Atherton PJ, Reeves ND, Flück M, Williams J, Mitchell WK, et al. Architectural, functional and molecular responses to concentric and eccentric loading in human skeletal muscle. Acta Physiol. 2014;210:642-54.

15. Franchi MV, Reeves ND, Narici MV. Skeletal muscle remodeling in response to eccentric vs. concentric loading: morphological, molecular, and metabolic adaptations. Front Physiol. 2017;8:1-16.

16. Gans $\mathrm{C}$, Bock W. The functional significance of muscle architecture - a theoretical analysis. Ergeb Anat Entwicklungsgesch. 1965;38:115-42.

17. Franchi MV, Longo S, Mallinson J, Quinlan JI, Taylor T, Greenhaff PL, et al. Muscle thickness correlates to muscle cross-sectional area in the assessment of strength traininginduced hypertrophy. Scand J Med Sci Sport. 2018;28:846-53.

18. Weiss LW. The use of B-mode ultrasound for measuring the thickness of skeletal muscle at two upper leg sites. J Orthop Sports Phys Ther. 1984;6:163-7.

19. Pimenta R, Blazevich AJ, Freitas SR. Biceps femoris long-head architecture assessed using different sonographic techniques. Med Sci Sports Exerc. 2018;50:2584-94.

20. Reeves ND, Maganaris CN, Narici MV. Ultrasonographic assessment of human skeletal muscle size. Eur J Appl Physiol. 2004;91:116-8.

21. Weng L, Tirumalai A, Lowery C, Nock L, Gustafson D, Von Behren P, et al. US extended-field-of-view imaging technology. Radiology. 1997;203:877-80.

22. Ahtiainen JP, Hoffren M, Hulmi JJ, Pietikäinen M, Mero AA, Avela $\mathrm{J}$, et al. Panoramic ultrasonography is a valid method to measure changes in skeletal muscle cross-sectional area. Eur J Appl Physiol. 2010;108:273-9.

23. Noorkoiv M, Nosaka K, Blazevich AJ. Assessment of quadriceps muscle cross-sectional area by ultrasound extended-fieldof-view imaging. Eur J Appl Physiol. 2010;109:631-9.

24. Scott JM, Martin DS, Ploutz-Snyder R, Caine T, Matz T, Arzeno NM, et al. Reliability and validity of panoramic ultrasound for muscle quantification. Ultrasound Med Biol. 2012;38:1656-61.

25. Kositsky A, Gonçalves BAM, Stenroth L, Barrett RS, Diamond LE, Saxby DJ. Reliability and validity of ultrasonography for measurement of hamstring muscle and tendon cross-sectional area. Ultrasound Med Biol. 2020;46:55-63.
26. Franchi MV, Fitze DP, Hanimann J, Sarto F, Spörri J. Panoramic ultrasound vs. MRI for the assessment of hamstrings cross - sectional area and volume in a large athletic cohort. Sci Rep. 2020;210:2715-27.

27. Nordez A, Jolivet E, Südhoff I, Bonneau D, De Guise JA, Skalli W. Comparison of methods to assess quadriceps muscle volume using magnetic resonance imaging. J Magn Reson Imaging. 2009;30:1116-23.

28. Evangelidis PE, Massey GJ, Pain MTG, Folland JP. Strength and size relationships of the quadriceps and hamstrings with special reference to reciprocal muscle balance. Eur J Appl Physiol. 2016;116:593-600.

29. Blazevich AJ, Coleman DR, Horne S, Cannavan D. Anatomical predictors of maximum isometric and concentric knee extensor moment. Eur J Appl Physiol. 2009;105:869-78.

30. Masuda K, Kikuhara N, Takahashi H, Yamanaka K. The relationship between muscle cross-sectional area and strength in various isokinetic movements among soccer players. J Sports Sci. 2003;21:851-8.

31. Maden-Wilkinson TM, Balshaw TG, Massey G, Folland JP. What makes long-term resistance-trained individuals so strong? A comparison of skeletal muscle morphology, architecture, and joint mechanics. J Appl Physiol. 2019;128:1000-11.

32. Fukunaga T, Miyatani M, Tachi M, Kouzaki M, Kawakami Y, Kanehisa H. Muscle volume is a major determinant of joint torque in humans. Acta Physiol Scand. 2001;172:249-55.

33. Stock MS, Thompson BJ. Echo intensity as an indicator of skeletal muscle quality: applications, methodology, and future directions. Eur J Appl Physiol. 2020;121(2):369-80.

34. Fragala MS, Kenny AM, Kuchel GA. Muscle quality in aging: a multi-dimensional approach to muscle functioning with applications for treatment. Sport Med. 2015;45:641-58.

35. Harris-love MO, Seamon BA, Teixeira C, Ismail C. Ultrasound estimates of muscle quality in older adults : reliability and comparison of Photoshop and ImageJ for the grayscale analysis of muscle echogenicity. PeerJ. 2016;4:e1721.

36. Lanferdini FJ, Manganelli BF, Lopez P, Klein KD, Cadore EL, Vaz MA. Echo intensity reliability for the analysis of different muscle areas in athletes. J Strength Cond Res. 2019;33:3353-60.

37. Mangine GT, Fukuda DH, LaMonica MB, Gonzalez AM, Wells AJ, Townsend JR, et al. Influence of gender and muscle architecture asymmetry on jump and sprint performance. J Sport Sci Med. 2014;13:904-11.

38. Mangine GT, Hoffman JR, Gonzalez AM, Jajtner AR, Scanlon $\mathrm{T}$, Rogowski JP, et al. Bilateral differences in muscle architecture and increased rate of injury in National Basketball Association players. J Athl Train. 2014;49:794-9.

39. Gonzales JM, Galpin AJ, Montgomery MM, Pamukoff DN. Comparison of lower limb muscle architecture and geometry in distance runners with rearfoot and forefoot strike pattern. J Sports Sci. 2019;37:2184-90.

40. Del Baño-Aledo ME, Martínez-Payá JJ, Ríos-Díaz J, MejíasSuárez S, Serrano-Carmona S, de Groot-Ferrando A. Ultrasound measures of tendon thickness: Intra-rater, inter-rater and inter-machine reliability. Muscles Ligaments Tendons J. 2017;7:192-9.

41. Reeves ND, Maganaris CN, Narici MV. Effect of strength training on human patella tendon mechanical properties of older individuals. J Physiol. 2003;548:971-81.

42. Mc Auliffe S, Mc Creesh K, Purtill H, O'Sullivan K. A systematic review of the reliability of diagnostic ultrasound imaging in measuring tendon size: Is the error clinically acceptable? Phys Ther Sport. 2017;26:52-63. 
43. Maganaris CN, Chatzistergos P, Reeves ND, Narici MV. Quantification of internal stress-strain fields in human tendon: unraveling the mechanisms that underlie regional tendon adaptations and mal-adaptations to mechanical loading and the effectiveness of therapeutic eccentric exercise. Front Physiol. 2017;8:91.

44. Biewener AA, Roberts TJ. Muscle and tendon contributions to force, work, and elastic energy savings: A Comparative perspective. Exerc Sport Sci Rev. 2000;28:99-107.

45. Seynnes OR, Bojsen-Møller J, Albracht K, Arndt A, Cronin NJ, Finni T, et al. Ultrasound-based testing of tendon mechanical properties: a critical evaluation. J Appl Physiol. 2015;118:133-41.

46. de Boer MD, Maganaris CN, Seynnes OR, Rennie MJ, Narici MV. Time course of muscular, neural and tendinous adaptations to 23 day unilateral lower-limb suspension in young men. J Physiol. 2007;583:1079-91.

47. Quinlan JI, Maganaris CN, Franchi MV, Smith K, Atherton PJ, Szewczyk NJ, et al. Muscle and tendon contributions to reduced rate of torque development in healthy older males. J Gerontol Ser A Biol Sci Med Sci. 2018;73:539-45.

48. Creze M, Nordez A, Soubeyrand M, Rocher L, Maître X, Bellin MF. Shear wave sonoelastography of skeletal muscle: basic principles, biomechanical concepts, clinical applications, and future perspectives. Skelet Radiol. 2018;47:457-71.

49. Lima K, Junior J, WCDA P, de Oliveira L. Assessment of the mechanical properties of the muscle-tendon unit by supersonic shear wave imaging elastography : a review. Ultrasonography. 2018;37:3-15.

50. Hug F, Tucker K, Gennisson JL, Tanter M, Nordez A. Elastography for muscle biomechanics: toward the estimation of individual muscle force. Exerc Sport Sci Rev. 2015;43:125-33.

51. Dubois G, Kheireddine W, Vergari C, Bonneau D, Thoreux P, Rouch P, et al. Reliable protocol for shear wave elastography of lower limb muscles at rest and during passive stretching. Ultrasound Med Biol. 2015;41:2284-91.

52. Prado-Costa R, Rebelo J, Monteiro-Barroso J, Preto AS. Ultrasound elastography: compression elastography and shear-wave elastography in the assessment of tendon injury. Insights Imaging. 2018;9:791-814.

53. Marcucci L, Reggiani C. Increase of resting muscle stiffness, a less considered component of age-related skeletal muscle impairment. Eur J Transl Myol. 2020;30:223-33.

54. Abe T, Fukashiro S, Harada Y, Kawamoto K. Relationship between sprint performance and muscle fascicle length in female sprinters. J Physiol Anthropol Appl Hum Sci. 2001;20:141-7.

55. Kumagai K, Abe T, Brechue WF, Ryushi T, Takano S, Mizuno M. Sprint performance is related to muscle fascicle length in male 100-m sprinters. J Appl Physiol. 2000;88:811-6.

56. Nasirzade A, Ehsanbakhsh A, Ilbeygi S, Sobhkhiz A, Argavani $\mathrm{H}$, Aliakbari M. Relationship between sprint performance of front crawl swimming and muscle fascicle length in young swimmers. J Sport Sci Med. 2014;13:550-6.

57. Alegre LM, Lara AJ, Elivira J, Aguado X. Muscle morphology and jump performance: gender and intermuscular variability. $\mathrm{J}$ Sports Med Phys Fitness. 2009;49(3):320-6.

58. Secomb J, Lungren L, Farley O, Tran T, Nimphius S, Sheppard J. Relationships between lower-body muscle stricture and lowerbody strength, power and muscle-tendon complex stiffness. J Strength Cond Res. 2015;29:2221-8.

59. Methenitis S, Zaras N, Spengos K, Stasinaki A, Karampatsos $\mathrm{G}$, Georgiadis G, et al. Role of muscle morphology in jumping, sprinting, and throwing performance in participants with different power training duration experience. J Strength Cond Res. 2016;30:807-17.
60. Ruiz-Cárdenas JD, Rodríguez-Juan JJ, Ríos-Díaz J. Relationship between jumping abilities and skeletal muscle architecture of lower limbs in humans: systematic review and meta-analysis. Hum Mov Sci. 2018;58:10-20.

61. Pentidis N, Mersmann F, Bohm S, Giannakou E, Aggelousis N, Arampatzis A. Effects of long-term athletic training on muscle morphology and tendon stiffness in preadolescence: association with jump performance. Eur J Appl Physiol. 2020;1-13.

62. Nuell S, Illera-Domínguez V, Carmona G, Alomar X, Padullés $\mathrm{JM}$, Lloret M, et al. Sex differences in thigh muscle volumes, sprint performance and mechanical properties in national-level sprinters. PLoS ONE. 2019;14:1-13.

63. Kubo K, Ikebukuro T, Yata H, Tomita M, Okada M. Morphological and mechanical properties of muscle and tendon in highly trained sprinters. J Appl Biomech. 2011;27:336-44.

64. Ritsche P, Bernhard T, Roth R, Lichtenstein E, Keller M, Zingg $\mathrm{S}$, et al. M. biceps femoris architecture and sprint ability in youth soccer players: a cross-sectional analysis. Int J Sports Physiol Perform (in press)

65. van der Zwaard S, Weide G, Levels K, Eikelboom MRI, Noordhof DA, Hofmijster MJ, et al. Muscle morphology of the vastus lateralis is strongly related to ergometer performance, sprint capacity and endurance capacity in Olympic rowers. J Sports Sci. 2018;36:2111-20.

66. Takahashi K, Wakahara T. Association between trunk and gluteus muscle size and long jump performance. PLoS ONE. 2019;14:1-13.

67. Kovács B, Kóbor I, Gyimes Z, Sebestyén Ö, Tihanyi J. Lower leg muscle-tendon unit characteristics are related to marathon running performance. Sci Rep. 2020;10:1-8.

68. Zaras N, Stasinaki A, Spiliopoulou P, Hdjicharalambous M, Terzis G. Lean body mass, muscle architecture, and performance in well-trained female weightlifters. Sports. 2020;8:1-9.

69. Nimphius S, McGuigan M, Newton R. Changes in muscle architecture and performance during a competitive season in female softball players. J Strength Cond Res. 2012;26:2655-66.

70. Blazevich AJ, Cannavan D, Coleman DR, Horne S. Influence of concentric and eccentric resistance training on architectural adaptation in human quadriceps muscles. J Appl Physiol. 2007;103:1565-75.

71. Noorkõiv M, Nosaka K, Blazevich AJ. Neuromuscular adaptations associated with knee joint angle-specific force change. Med Sci Sports Exerc. 2014;46:1525-37.

72. Impellizzeri FM, Marcora SM, Coutts AJ. Internal and external training load: 15 years on. Int J Sports Physiol Perform. 2019;14:270-3.

73. Narici MV, Roi GS, Landoni L, Minetti AE, Cerretelli P. Changes in force, cross-sectional area and neural activation during strength training and detraining of the human quadriceps. Eur J Appl Physiol Occup Physiol. 1989;59:310-9.

74. Seynnes OR, De Boer M, Narici MV. Early skeletal muscle hypertrophy and architectural changes in response to highintensity resistance training. J Appl Physiol. 2007;102:368-73.

75. Monti E, Franchi MV, Badiali F, Quinlan JI, Longo S, Narici MV. The time-course of changes in muscle mass, architecture and power during 6 weeks of plyometric training. Front Physiol. 2020;11:1-14.

76. Franchi MV, Atherton PJ, Maganaris CN, Narici MV. Fascicle length does increase in response to longitudinal resistance training and in a contraction-mode specific manner. Springerplus Springer Int Publ. 2016;5:1-3.

77. Franchi MV, Ruoss S, Valdivieso P, Mitchell KW, Smith K, Atherton PJ, et al. Regional regulation of focal adhesion kinase 
after concentric and eccentric loading is related to remodelling of human skeletal muscle. Acta Physiol. 2018;223:e13056.

78. Alegre LM, Ferri-Morales A, Rodriguez-Casares R, Aguado $\mathrm{X}$. Effects of isometric training on the knee extensor momentangle relationship and vastus lateralis muscle architecture. Eur J Appl Physiol. 2014;114:2437-46.

79. Mendiguchia J, Conceicao F, Edouard P, Fonseca M, Pereira R, Id HL. Sprint versus isolated eccentric training : Comparative effects on hamstring architecture and performance in soccer players. PLoS ONE. 2020;15:1-19.

80. Coratella G, Beato M, Milanese C, Longo S, Limonta A, Rampichini S, et al. Specific adaptations in performance and muscle architecture after weighted jump-squat vs. body mass squat jump training in recreational soccer players. J Strength Cond Res. 2018;32:921-9.

81. Blazevich AJ, Gill ND, Bronks R, Newton RU. Trainingspecific muscle architecture adaptation after 5-wk training in athletes. Med Sci Sports Exerc. 2003;35:2013-22.

82. Magnusson SP, Kjaer M. The impact of loading, unloading, ageing and injury on the human tendon. J Physiol. 2019;5:1283-98.

83. Wiesinger HP, Kösters A, Müller E, Seynnes OR. Effects of increased loading on in vivo tendon properties: a systematic review. Med Sci Sports Exerc. 2015;47:1885-95.

84. Aeles J, Lenchant S, Vanlommel L, Vanwanseele B. Bilateral differences in muscle fascicle architecture are not related to the preferred leg in jumping athletes. Eur J Appl Physiol. 2017; 117:1453-61.

85. Mersmann F, Charcharis G, Bohm S, Arampatzis A. Muscle and tendon adaptation in adolescence: elite volleyball athletes compared to untrained boys and girls. Front Physiol. 2017;8:1-11.

86. Mersmann F, Laube G, Bohm S, Arampatzis A. Muscle and tendon morphology in early-adolescent athletes and untrained peers. Front Physiol. 2020;11:1-8.

87. Monti E, Toniolo L, Marcucci L, Bondì M, Martellato I, Šimunič B, et al. Are muscle fibres of body builders intrinsically weaker? A comparison with single fibres of aged-matched controls. Acta Physiol. 2020; 13557.

88. Fukutani A, Tsuruhara Y, Miyake Y, Takao K, Nagano A, Isaka T. Comparison of the relative muscle volume of triceps surae among sprinters, runners, and untrained participants. Physiol Rep. 2020;6-11.

89. Charcharis G, Mersmann F, Bohm S, Arampatzis A. Morphological and mechanical properties of the quadriceps femoris muscle-tendon unit from adolescence to adulthood: effects of age and athletic training. Front Physiol. 2019;10:1-12.

90. Karamanidis K, Epro G. Monitoring muscle-tendon adaptation over several years of athletic training and competition in elite track and field jumpers. Front Physiol. 2020;11:1675.

91. Brughelli M, Cronin J, Nosaka K. Muscle architecture and optimum angle of the knee extensors: a comparison between cyclists and Australian Rules football players. J Strength Cond Res. 2010;24:717-21.

92. Panidi I, Bogdanis GC, Gaspari V, Spiliopoulou P, Donti A, Terzis G, et al. Gastrocnemius medialis architectural properties in flexibility trained and not trained child female athletes: a pilot study. Sports. 2020;8:29.

93. Avrillon S, Lacourpaille L, Hug F, Le Sant G, Frey A, Nor$\operatorname{dez} \mathrm{A}$, et al. Hamstring muscle elasticity differs in specialized high-performance athletes. Scand J Med Sci Sport. 2020;30:83-91.

94. Wiesinger HP, Rieder F, Kösters A, Müller E, Seynnes OR. Are sport-specific profiles of tendon stiffness and cross-sectional area determined by structural or functional integrity? PLoS ONE. 2016;11:1-16.
95. Kongsgaard M, Aagaard P, Kjaer M, Magnusson SP. Structural Achilles tendon properties in athletes subjected to different exercise modes and in Achilles tendon rapture patients. J Appl Physiol. 2005;99:1965-71.

96. Arampatzis A, Karamanidis K, Morey-Klapsing G, De Monte $\mathrm{G}$, Stafilidis S. Mechanical properties of the triceps surae tendon and aponeurosis in relation to intensity of sport activity. J Biomech. 2007;40:1946-52.

97. Wiesinger HP, Rieder F, Kösters A, Müller E, Seynnes OR. Sport-specific capacity to use elastic energy in the patellar and Achilles tendons of elite athletes. Front Physiol. 2017;8:1-10.

98. Visnes H, Tegnander A, Bahr R. Ultrasound characteristics of the patellar and quadriceps tendons among young elite athletes. Scand J Med Sci Sport. 2015;25:205-15.

99. Bazyler C, Mizuguchi S, Harrison A, Sato K, Kavanaugh A, DeWeese $\mathrm{BH}$, et al. Changes in muscle architecture, explosive ability, and track and field throwing performance throughout a competitive season after a taper. J Strength Cond Res. 2017;31:2785-93.

100. Bazyler C, Mizuguchi S, Sole C, Suchomel TJ, Sato K, Kavanaugh A, et al. Jumping performance is preserved but not muscle thickness in collegiate volleyball players after a taper. $\mathrm{J}$ Strength Cond Res. 2017;32:1020-8.

101. Mersmann F, Bohm S, Schroll A, Boeth H, Duda GN, Arampatzis A. Muscle and tendon adaptation in adolescent athletes: a longitudinal study. Scand J Med Sci Sport. 2017;27:75-82.

102. Rudavsky A, Cook J, Docking S. Quantifying proximal patellar tendon changes during adolescence in elite ballet dancers, a 2-year study. Scand J Med Sci Sport. 2018;28:2369-74.

103. Kalkhoven JT, Watsford ML, Impellizzeri FM. A conceptual model and detailed framework for stress-related, strain-related, and overuse athletic injury. J Sci Med Sport. 2020.

104. Timmins RG, Bourne MN, Shield AJ, Williams MD, Lorenzen C, Opar DA. Short biceps femoris fascicles and eccentric knee flexor weakness increase the risk of hamstring injury in elite football (soccer): a prospective cohort study. Br J Sports Med. 2016;50:1524-35.

105. Timmins R, Shield AJ, Williams MD, Lorenzen C, Opar DA. Biceps femoris long head architecture: a reliability and retrospective injury study. Med Sci Sports Exerc. 2015;47(5):905-13.

106. Franchi MV, Fitze DP, Raiteri BJ, Hahn D, Sporri J. Ultrasoundderived biceps femoris long head fascicle length: extrapolation pitfalls. Med Sci Sport Exerc. 2019;52(1):233-43.

107. Sarto F, Monti E, Simunič B, Pišot R, Narici MV, Franchi MV. Changes in Biceps Femoris Long Head Fascicle Length after 10-day Bed Rest Assessed with Different Ultrasound Methods. Med Sci Sport Exerc. 2021:1-9. https://doi.org/10.1249/ MSS.0000000000002614

108. Hides JA, Brown CT, Penfold L, Stanton WR. Screening the lumbopelvic muscles for a relationship to injury of the quadriceps, hamstrings, and adductor muscles among elite Australian Football League players. J Orthop Sports Phys Ther. 2011;41:767-75.

109. Hides JA, Stanton WR. Can motor control training lower the risk of injury for professional football players? Med Sci Sports Exerc. 2014;46:762-8.

110. Hides JA, Stanton WR, Mendis MD, Franettovich Smith MM, Sexton MJ. Small multifidus muscle size predicts football injuries. Orthop J Sport Med. 2014;2:1-9.

111. Hides JA, Stanton WR. Predicting football injuries using size and ratio of the multifidus and quadratus lumborum muscles. Scand J Med Sci Sport. 2017;27:440-7.

112. Peterhans L, Fröhlich S, Stern C, Frey WO, Farshad M, Sutter R, et al. High rates of overuse-related structural abnormalities in the lumbar spine of youth competitive alpine skiers: a cross-sectional MRI study in 108 athletes. Orthop J Sport Med. 2020;8:1-10. 
113. Aubry S, Nueffer J, Tanter M, Becce F, Vidal C, Michel F. Viscoelasticity in achilles tendonopathy: quantitative assessment by using real-time. Radiology. 2015;274:821-9.

114. Chen X, Cui L, He P, Shen W, Qian Y, Wang J. Shear wave elastographic characterization of normal and torn achilles tendons. J Ultrasound Med. 2013;449-55.

115. Coombes BK, Hug ANF, Tucker K, Vicenzino B. Achilles and patellar tendinopathy display opposite changes in elastic properties : a shear wave elastography study. Scand J Med Sci Sports. 2018;1201-8.

116. Ooi C, Richards P, Mafulli N, Ede D, Schneider M, Connell D, et al. A soft patellar tendon on ultrasound elastography is associated with pain and functional deficit in volleyball players. J Sci Med Sport. 2015;19:373-8

117. Dirrichs T, Quack V, Gatz M, Tingart M, Kuhl CK, Schrading S. Shear wave elastography (SWE) for the evaluation of patients with tendinopathies. Acad Radiol. 2016;23:1204-13.

118. Rosskopf A, Ehrmann C, Buck FM, Gerber C, Flück M, Pfirrmann C. Quantitative shear-wave US elastography of the supraspinatus muscle: reliability of the method and relation to tendon integrity and muscle quality. Radiology. 2016;000:1-10.

119. Kocygit F, Kuyucu E, Kocygit Herek D, Savkin R, Aslan U. Investigation of biomechanical characteristics of intact supraspinatus tendons in subacromial impingement syndrome. Am J Phys Med Rehabil. 2016;95(8):1-9.

120. Leong HT, Hug F, Fu SN. Increased upper trapezius muscle stiffness in overhead athletes with rotator cuff tendinopathy. PLoS One. 2016;11(5):1-13.

121. Hou SW, Merkle AN, Babb JS, McCabe R, Gyftopoulos S, Adler RS. Shear wave ultrasound elastographic evaluation of the rotator cuff tendon. J Ultrasound Med. 2017;36:95-106.

122. Balaban M, Idilman IS, Ipek A, Ikiz SS, Bektaser B, Gumus M. Elastographic findings of achilles tendons in asymptomatic professional male volleyball players. J Ultrasound Med. 2016;35:2623-8.

123. Ooi C, Schneider ME, Malliaras P, Jones D, Saunders S, Mcmahon A, et al. Sonoelastography of the achilles tendon : prevalence and prognostic value among asymptomatic elite Australian rules football players. Clin J Sport Med. 2016;26:299-306.

124. Ooi CC, Schneider ME, Malliaras P, Counsel P, Connell DA. Prevalence of morphological and mechanical stiffness alterations of mid Achilles tendons in asymptomatic marathon runners before and after a competition. Skelet Radiol. 2015;44:1119-27.

125. Ranger TA, Cicuttini FM, Jensen TS, Peiris WL, Hussain SM, Fairley J, et al. Are the size and composition of the paraspinal muscles associated with low back pain? A systematic review. Spine J. 2017;17:1729-48.

126. Ranger TA, Cicuttini FM, Jensen TS, Heritier S, Urquhart DM. Paraspinal muscle cross-sectional area predicts low back disability but not pain intensity. Spine J. 2019;19:862-8.

127. Murillo C, Falla D, Sanderson A, Rushton A, Heneghan NR. Shear wave elastography investigation of multifidus stiffness in individuals with low back pain. J Electromyogr Kinesiol. 2019;47:19-24

128. Koppenhaver S, Gaffney E, Oates A, Eberle L, Young B, Hebert $\mathrm{J}$, et al. Lumbar muscle stiffness is different in individuals with low back pain than asymptomatic controls and is associated with pain and disability, but not common physical examination findings. Musculoskelet Sci Pract. 2020;45.

129. Kitamura G, Tateuchi H, Ichihashi N. Greater lumbar extension during dolphin kick and psoas major tightness in swimmers with low back pain. J Sport Rehabil. 2019;29:716-22.
130. Howard EE, Pasiakos SM, Fussell MA, Rodriguez NR. Skeletal muscle disuse atrophy and the rehabilitative role of protein in recovery from musculoskeletal injury. Adv Nutr. 2020;4:1-13.

131. Milsom J, Barreira P, Brugess D, Iqbal Z, Morton J. Case study: muscle atrophy and hypertrophy in a Premier League soccer player during rehabilitation from ACL injury. Int J Sport Nutr Exerc Metab. 2014;24:543-52.

132. Konrath JM, Vertullo CJ, Kennedy BA, Bush HS, Barrett RS, Lloyd DG. Morphologic characteristics and strength of the hamstring muscles remain altered at 2 years after use of a hamstring tendon graft in anterior cruciate ligament reconstruction. Am J Sports Med. 2016;44:2589-98.

133. Nomura Y, Kuramochi R, Fukubayashi T. Evaluation of hamstring muscle strength and morphology after anterior cruciate ligament reconstruction. Scand J Med Sci Sport. 2015;25:301-7.

134. Norte GE, Knaus KR, Kuenze C, Handsfield GG, Meyer CH, Blemker SS, et al. MRI-based assessment of lower-extremity muscle volumes in patients before and after ACL reconstruction. J Sport Rehabil. 2018;27:201-12.

135. Morris N, Jordan MJ, Sumar S, Adrichem B, Heard M, Herzog W. Joint angle-specific impairments in rate of force development, strength, and muscle morphology after hamstring autograft. Transl Sport Med. 2020;4(1):1-11.

136. Silder A, Heiderscheit BC, Thelen DG, Enright T, Tuite MJ. MR observations of long-term musculotendon remodeling following a hamstring strain injury. Skelet Radiol. 2008;37:1101-9.

137. Bourne MN, Opar DA, Williams MD, Najjar AA, Shield AJ. Muscle activation patterns in the Nordic hamstring exercise : impact of prior strain injury. Scand J Med Sci Sports. 2016;26:666-74.

138. Sanfilippo JL, Slider A, Sherry MA, Tuite M, Heiderscheit BC. Hamstring strength and morphology progression after return to sport from injury. Med Sci Sports Exerc. 2014;45:448-54.

139. Setuain I, Izquierdo M, Idoate F, Bikandi E, Gorostiaga EM, Aagaard P, et al. Differential effects of two rehabilitation programs following anterior cruciate ligament reconstruction. J Sport Rehabil. 2016;26:544-55.

140. Hullfish TJ, O'Connor KM, Baxter JR. Gastrocnemius fascicles are shorter and more pennate throughout the first month following acute achilles tendon rupture. PeerJ. 2019;29(7).

141. Avrillon S, Hug F, Guilhem G. Bilateral differences in hamstring coordination in previously injured elite athletes. J Appl Physiol. 2020;128:688-97.

142. Maganaris $\mathrm{CN}$. Tendon conditioning: artefact or property? Proc R Soc B Biol Sci. 2003;270:39-42.

143. Ikezoe T, Kobayashi T, Nakamura M, Ichihashi N. Effects of low-load, higher-repetition versus high-load, lower-repetition resistance training not performed to failure on muscle strength, mass, and echo intensity in healthy young men: a time-course study. J Strength Cond Res. 2017;34:3439-45.

144. MacLennan RJ, Sahebi M, Becker N, Davis E, Garcia JM, Stock MS. Declines in skeletal muscle quality vs. size following two weeks of knee joint immobilization. PeerJ. 2020;8:1-19.

145. Brum J, Bernal M, Gennisson JL, Tanter M. In vivo evaluation of the elastic anisotropy of the human Achilles tendon using shear wave dispersion analysis. Phys Med Biol. 2014;59:505-23.

146. Aubry S, Risson JR, Kastler A, Barbier-Brion B, Siliman G, Runge $\mathrm{M}$, et al. Biomechanical properties of the calcaneal tendon in vivo assessed by transient shear wave elastography. Skelet Radiol. 2013;42:1143-50.

147. Kot BCW, Zhang ZJ, Lee AWC, Leung VYF, Fu SN. Elastic modulus of muscle and tendon with shear wave ultrasound elastography: variations with different technical settings. PLoS One. 2012;7. 
148. Blazevich AJ, Gill ND, Zhou S. Intra- and intermuscular variation in human quadriceps femoris architecture assessed in vivo. J Anat. 2006;209:289-310.

149. Finni T, Ikegaw S, Lepola V, Komi P. In vivo behavior of vastus lateralis muscle during dynamic performances. Eur J Sport Sci. 2001;1:1-13.

150. Herbert RD, Clarke J, Kwah LK, Diong J, Martin J, Clarke EC, et al. In vivo passive mechanical behaviour of muscle fascicles and tendons in human gastrocnemius muscle-tendon units. $\mathbf{J}$ Physiol. 2011;589:5257-67.

151. Treece GM, Gee AH, Prager RW, Cash CJC, Berman LH. High-definition freehand 3-D ultrasound. Ultrasound Med Biol. 2003;29:529-46.

152. Bolsterlee B, Gandevia SC, Herbert RD. Effect of transducer orientation on errors in ultrasound image-based measurements of human medial gastrocnemius muscle fascicle length and pennation. PLoS One. 2016;11.

153. Bolsterlee B, Gandevia SC, Herbert RD. Ultrasound imaging of the human medial gastrocnemius muscle: how to orient the transducer so that muscle fascicles lie in the image plane. J Biomech. 2016;49:1002-8.

154. Adkins AN, Murray WM. Obtaining quality extended field-ofview ultrasound images of skeletal muscle to measure muscle fascicle length. J Vis Exp. 2020;166:1-16.

155. Seynnes OR, Cronin NJ. Simple muscle architecture analysis (SMA): An ImageJ macro tool to automate measurements in B-mode ultrasound scans. PLoS ONE. 2020;15:1-13. 